\title{
Formal and Informal Analysis of Rendered Space: The Basilica Portuense
}

\author{
Graeme Earl, Vito Porcelli, Constantinos Papadopoulos, Gareth Beale, \\ Matthew Harrison, Hembo Pagi and Simon Keay \\ Archaeological Computing Research Group, Faculty of Humanities, \\ University of Southampton, UK
}

\section{Introduction}

Digital archaeological analyses of space have proceeded traditionally from two distinct perspectives. First, there has been a phenomenological appraisal of computer graphic modelled geometry, and second a formal analysis of the surviving spaces and extrapolations from them. The former approach encompasses work on the visualisation of raw geometric data captured through techniques such as laser scanning and photogrammetry. In addition it has considered to be significant the process and interfaces within which extrapolations from these data take place - namely the construction of increasingly sophisticated graphical simulations in software such as 3ds Max, Maya and Vue Infinite. Finally, it draws upon the ability of such software and interactive visualisation tools to stimulate new interpretations through interaction with the visualised geometry. This virtual phenomenology in turn has been seen to be significantly enhanced by an emphasis on physical realism (Chalmers 2002), but has not been without its critics (Lock 2003). The physically realistic approach extends methodologies primarily stimulated by the architectural community to enable comparisons between built architecture (and their resulting spatial interactions), to evaluate their robusticity through stochastic methods, and to predict and analyse physical factors such as lighting in architectural designs. The novel research in physical (or "predictive") rendering is primarily constrained to the domain of computer graphics (Wilkie et al 2009).

Archaeology has made use of both sets of methods and with growing capture of threedimensional data and greater computational resources on the archaeologist's desktop so they have proliferated. In this paper we introduce an integrated method drawing on all of the above techniques in order to address questions both of archaeological modelling practice, and the analysis of their outputs. As a case study the paper explores the Basilica Portuense at the site of Portus, Italy. The paper begins by identifying the interpretative context for the simulation and analysis of three-dimensional digital forms. It considers the potential of approaches focussed on visibility and lighting within these environments. The paper then outlines the case study and in particular focuses on areas of uncertainty explored in the analyses. Issues of uncertainty and the potentials of procedural modelling are outlined. Three methodological approaches are then explored - formal visibility analysis via Texture Viewsheds (Earl 2005), lighting analysis and finally a more phenomenological appraisal of the structure using physically accurate graphics. Finally, we identify conclusions and future work in these domains. 


\section{D Modelling for Spatial Interpretation}

\section{Visibility}

The creation of modelled landscapes and built-environments has enabled a wide range of formal analyses of visibility. Paliou (this volume) provides a comprehensive overview of such formal methods, including both pseudo- and true three-dimensional spatial analyses. In this paper we develop the Texture Viewsheds (Earl 2005) method outlined by Paliou and identify the benefits of comparing such visibility products with lighting analysis and more subjective appraisals of modelled space. The formal visibility methods correspond to a great extent with the Llobera's (2003) concept of visualscape outlined in Paliou (this volume). In particular our approach is designed to provide analytical detail for the total environment of the Basilica Portuense and sub-sections of it, is inherently three-dimensional, and enables the analytical products to be remapped onto the modelled geometry upon which they are based. It also builds on the three-dimensional methods outlined by Paliou and Knight (forthcoming) at the Basilica of San Vitale.

Paliou (this volume) considers the potential of approaches such as isovists and VGA that summarise but are not based on true three-dimensional representations of space. Our contribution complements these formal approaches, including those used in the religious spaces defined by Clark (2007a; 2007b) and Richardson (2003). It should also be considered in the context of Allison's (2001) critique of formal methods in a Roman context and Giles' (2007) detailed critique of visual analyses. Giles identifies the need to consider pre-modern visuality, multi-modal understandings of space and of the bias in current methods, including those outlined here, towards modern visual sense. We shall return to these issues in the conclusions to this paper but we propose that what follows should first be read in the light of this compelling critique.

\section{Lighting and physical accuracy}

\section{Simulation}

Lighting is increasingly seen as a method both of formal appraisal of archaeological environments and of accurate simulation of their appearance. At the core of this lies an attempt to simulate the physical transport of light within a scene to a degree that quantitative appraisals of a modelled environment such as the amount of available light and the colour of a perceived object closely parallel those obtained experimentally in an equivalent real space. Such quantitatively robust outputs are in turn used to justify the direct use of simulated environments in the analysis of spatial experience.

Research in physical accuracy of lighting in archaeological environments is exemplified in the work of Devlin $(2001,2002)$ and Chalmers (2002). The work of Chalmers has focussed on increasingly physically-accurate simulation of light transport and of all components of the visual scene. A physically accurate scene in this sense should provide means to introduce physically accurate artificial and natural lighting (Kider et al 2009, Masuda and Yamada 2004, Sundstedt et al. 2004, Zányi 2007; cf. Dawson et al 2007). In addition the light created by such luminaires should react appropriately with the scene. Thus, smoke and dust particles should influence them (Gutierrez et al 2008, Hawkins et al 2005), the illumination of the surrounding environment such as the sky (Happa et al 2009), and environmental factors such as rain should behave accurately in the scene (Wang et al 2006; Garg and Nayar 2006). The light should react with surfaces in ways appropriate to their physical form - for example, the colour expressed as the dynamic range of the surface materials (Happa 2009; Happa et al 2010), the surface reflectance properties (Müller et al 2005, Callet et al 2010), the scattering of light within materials such as marble and skin (Hašan et al 2010) and the perception of 
these as a function of motion, depth of focus and accommodation to brightness (Ledda et al 2004; Chalmers et al 2007). Those most interested in near-perfect digital replication of complex surface/ light interactions (for example gemstone workers) are increasingly adopting spectral approaches that represent the complex interactions that are also of significance in archaeological contexts - for example, dispersion in glass and lithic objects, absorption and metemerism (Weidlich and Wilkie 2008). More recently work in physically real simulation has also incorporated the potentials of multi-modal environments that include touch, sound and smell alongside visual stimuli (Chalmers and Zányi 2009).

It is not however the case that all problems in creating physically accurate scenes have been overcome. First, there remains only limited work in the formal validation of digital constructed cultural heritage. Whilst some studies have demonstrated, for example, the impact of motion or high dynamic range imagery on perception of modelled objects (Hasic et al 2010) there remains very little coherent study. In particular studies of the perception of individual surface types (for example marble) remain isolated from the cultural heritage questions to which they pertain. For example, how does the marble behave under particular illumination in a particular cultural heritage environment? The work of Kider (et al 2009) discussed above goes some way in this but does not provide a quantitative, perceptually driven summary. Similarly innovations in physical simulation of measured marble BRDF shows promise in enabling ground-truthed testing of measured and analytical BRDF models (Dong et al 2010), but is only at an early stage. For example, one might produce a physical replica object of one of the components of the Basilica Portuense scene that exhibits subsurface scattering and compare its interaction to real light sources to the predicted CG model (Hašan et al 2010)). Although both are based on the same BRDF model the interaction with the physical luminaire would be of considerable value, if the technique were to be more widely implemented.

The second problem in creating physically accurate cultural heritage environments is algorithmic. In many cases cultural heritage research questions have aligned very well with computer graphic innovations in modelling and rendering. However, given the expense of such research, where adjacencies do not always exist innovation can be slow. Indeed, even where a need beyond cultural heritage exists it may be that research has not been undertaken for other reasons. For example, as Happa (et al 2009) notes there is limited research in rendering environments with very low lighting levels, including environments at night. Many of the luminaires associated with archaeological environments function at such low energy levels that the algorithms available, and indeed the hardware to consume and interact with them, are less well developed than in environments lit by modern artificial luminaires.

The final problem remains access to data of sufficient quality to merit the use of physically accurate simulations. Research at the forefront of computer graphics commonly employs nonstandard capture devices and makes use of file formats that are particular to only limited workflows. Thinking only of the research identified above in terms of physically accurate rendering one would ideally need to obtain a spectrophotometer, colour charts and grey cards, HDRI image probes, high dynamic video, an HDRI monitor, and a gonio-reflectometer in order to obtain the requisite data. These are only a small subset of the tools required to produce physically accurate simulations. Indeed it is even possible to make use of the physical properties of an object such as a bronze writing tablet to enable spectral rendering (Robin et al 2010). Furthermore, whilst the software commonly available to archaeologists has become extremely powerful, for necessary ease-of-use and robusticity reasons it is difficult to modify these to accommodate the latest advances in lighting and rendering. So, even where computer graphics work has produced freely-available metrics corresponding to particular common cultural heritage materials, for example the MERL (Matusik 2005) and 
CUReT (CURET) measured BRDF databases, the means to apply these within a cultural heritage domain are limited. We are therefore constrained in most of our work to physical analytical BRDF (and BSSRDF) models.

Despite these problems it is our belief that the value of such physically accurate studies lies in the sense that the viewer has a more direct appraisal of the scene than one where the simulation lacks this physical rigour. Appearance of photorealism has little value if that appearance has no quantifiable validity, unless the research process is explicitly to be informed by the production of archaeologically-informed works of digital art. Furthermore Chalmers has also defined "authentic illumination" (Chalmers et al 2006) as a composite of this accurate physical simulation of light transport with data that have been well researched and which are therefore believed to provide a good representation of the physical form and components of the space when constructed or used. By valuing such physical characteristics one is inevitably drawn to an interpretation of perception that persists through time, rather than one which is entirely temporally and culturally contingent. However, it is rarely the case that such studies propose to recreate the past as it was but rather to create representations that can at least be validated archaeologically and physically to be faithful to the evidence. The directions such representations can be taken in depend on the epistemological direction of the research of which they form a part. For example, Dobbins and Gruber (forthcoming) present simulations of the "Drinking Contest at Antioch" and the House of the Faun at Pompeii. These studies concentrate on comparative analyses of shadows and the impact of this on a contextual appreciation and appraisal of mosaic decorations. Kider (et al 2009) identified the accurate simulation of pools of light as being of crucial significance in archaeological interpretations of spatial function and of social interaction as mediated by environment. Finally, Callet (et al 2010) explored the possibility of distinct light design in medieval contexts.

\section{Analysis}

The majority of work in the area of archaeological lighting relates to the production of attractive images of the type outlined above. However, the same technologies used to define patterns of colour, light and shade on a rendered scene can be used to provide metrics indicating the motion and impact of light energy within the same scene. Indeed it is a necessary component of the physically accurate rendering process that such simulations are undertaken. Formal lighting analysis halts the rendering process once light has been propagated within a scene and instead of producing a simulation of the resultant perceived colour for each point in space it provides a numerical summary of the energy distributed. This ability is vital to lighting designers, whether for the production of a lighting scheme for a new building or a theatrical production. The cost of construction and the very limited margins for error and modifications mean that lighting studies are a habitual part of the design process. As a consequence their physical accuracy is essential.

A small number of research projects have attempted to employ these formal analysis tools in an archaeological context, in order to quantify the quality and amount of light available in particular areas and the potential impact of such lighting on the behaviour in them. The work by Dawson (et al 2007; Dawson and Levy 2005) explored taskscapes in arctic houses through the simulation of structures and of their illumination. We employed similar techniques in work at the Minoan cemetery site at Phourni in Crete (Papadopoulos 2010; Papadopoulos and Earl 2009), creating multiple alternatives to explore and analyse. More recently work by us at Zominthos' ceramics workshop (Papadopoulos and Sakellarakis forthcoming) used lighting analysis to explore the relationship between tasks and illumination. Critiques of such taskfocussed approaches centre on the relevance of modern, Western lighting statistics to 
simulated past environments and behaviours. We agree that this poses questions for interpretation but do not agree that they cannot provide useful, optics and perceptually-based starting points for critique and development, particularly when positioned in broader ethnographic frameworks (as in Papadopoulos and Earl forthcoming).

\section{Methods}

For the analyses described below we chose to use 3ds Max Design 2011 which has a number of tools tailored to architectural spaces. The lighting analyses make use of a simulation of the light energy within the scene, taking into account the luminaires, environmental effects and the materials with which the light energy interacts. Two sets of statistics are commonly produced by such lighting analyses. Firstly, the illuminance or light arriving at a surface, commonly divided into the direct illuminance (i.e.the light that travels from the luminaire to the surface without any intervening reflections) and the indirect illuminance (which summarises the light reflected from surfaces but not received direct from the light source). Secondly, the luminance - the light that reflects from an illuminated surface.

The accuracy of lighting analyses depends on a number of factors:

1. Environmental effects such as participating media and the atmosphere;

2. Fit of simulated luminaire to its real world equivalent, in terms of energy and light distribution (particularly difficult when employing ancient light sources that may well have no experimentally-derived CIE or other metrics);

3. Quality of geometry defining the space analysed;

4. Quality of the material approximations employed;

5. Quality of the (necessarily approximate) solution calculating the interactions between these variables.

For this and previous papers we undertook detailed comparisons of the considerable impact of each of these factors on the lighting metrics. The relationship between the factors is also extremely complex, particularly given the many parameters associated with each. For example, the approximations present within the various Mental Ray rendering solutions includes numerous parameters (including those associated with caustic and global illumination photons), in contrast to the implementation of the iRay path tracing rendering mode.

Similarly only materials accurately simulating energy absorption, opacity, sub-surface scattering, refraction and reflection should be used in an environment where lighting analysis is undertaken. Solutions such as BTF (Dana et al 1999) and BRDF implementations in physically accurate .mi shaders enable more accurate approximations to the complexities of these interactions, but they remain approximations. Similarly, whilst increasing possibilities are emerging for spectral rendering (including a Mental Ray colour space and systems such as Maxwell) the availability of the necessary spectral surface reflectance and luminaire data limits their application where novel data collection is not possible. Each one of these factors will directly impact the energy simulation within the solution. However, for the sake of brevity we do not outline these here. Overall, we have found that use of the Iridis 3 supercomputer using Windows HPC has enabled generation of high fidelity solutions throughout the process and the nVidia CUDA optimisation of iRay on the Iridis3 GPU nodes is of significant value, both in terms of quality and speed of simulation. 


\section{The Basilica Portuense}

The imperial town of Portus was established to support the increasing flow of goods from across the Mediterranean through Rome, and as a redistribution hub for the empire as a whole. The archaeological remains of the port are situated north-west of the Republican river port of Ostia on the Tyrrhenian sea and about twenty-five kilometres from Rome. The port included warehouses, baths, houses and apartments, and the structures needed for the loading, unloading and administration of goods. Among these, an Early-Christian basilica has been identified to the south of the entrance to the hexagonal Trajanic basin, adjacent to the transverse canal linking the port, via a further canal, to the River Tiber. The basilica stood in an area that appears to have been dominated by commercial, administrative and storage buildings, some of which were converted to create the basilica (Paroli L. 2005: 258) (Figure 1). Computer simulation work on the basilica forms one part of the wider Portus and Portus in the Roman Mediterranean AHRC projects that incorporate computer applications throughout (Earl et al in press).

Throughout its early history the building underwent a series of transformations. Its final shape was characterised by three naves, with an apse at the end of the central nave. This was divided from the lateral aisles by means of ten pairs of columns, while the façade presented a triforium entrance. The basilica remained in use during the Middle Ages, in part as a consequence of restoration work in the eleventh and twelfth centuries. It began to be abandoned in the thirteenth century (Borrello et al 2002: 1267). In recent years the site was excavated and interpreted by a group of archaeologists under the direction of Dr Lidia Paroli of the Soprintendenza dei Beni Culturali di Ostia. The hypothesised architectural schemas explored here are based on her work and on the interpretations of the architects Dr Roberta Loreti and Dr Giuliana Irace.

Such transformation is not unusual in the development of early Christian places of worship. The first Christians living in the Roman provinces could not profess their religion freely and secret meetings were regularly attended. For three centuries they suffered persecution, most notably under Diocletian. Eventually, Christians gained their freedom of religion with the Edict of Milan, in 313 A.D. This led to the adaptation of many ancient buildings around the empire for the Christian's liturgies, particularly domuses, which were donated by the Roman Aristocracy as sign of devotion to the God (Fiocchi Nicolai 2001: 93). These "Titularis" basilicas took their names from aristocratic citizens who, after converting to Christianity, supplied properties and furniture and supporting the construction of the churches themselves. Many examples are still present, including several in Rome, such as Titulus Sabinae (Basilica of Santa Sabina), Titulus Lucinae (Basilica of San Lorenzo in Lucina), Titulus Vestinae (Basilica of San Vitale) and Titulus Clementi (Basilica of San Clemente). A similar history is proposed for the Early-Christian Basilica Portuense which may have been part of the Tituli Pammachii. In fact, the building was identified as an ancient guest-house for pilgrims in the "Xenodochium of Pammachius" by Rodolfo Amedeo Lanciani (1866, 100-3), with a dedication to Saint Peter and Saint Paul as proposed by Fevrier (1958, 316). Giovanni Battista De Rossi (1866: 99-100) suggested the dedication was actually to the Virgin Mary and that the construction of the basilica was against a hospice. The later excavations have endorsed this thesis although there remains uncertainty.

In the earliest phases of the 'basilica' a central and smaller building occupied the actual central area of the church. This building survived a variety of modifications in the first and second centuries (see Paroli L 2005. figure 7.19-7.20) (Figure 2). Later, many sections of the building described were reused and adapted to construct a newer and longer building, which, given the shape, was probably still utilised for commercial or administrative purposes (Figure 3). Transformation into a basilica is attributed to the end the second half of the fourth century 
(Paroli L 2005: 261). This was composed of eight pairs of columns with unfluted shafts and composite capitals with curled acanthus leaves. These divided a central and wider aisle from two narrower side aisles, with a narthex and a number of side doors (Figure 4). At the beginning of the fifth century two lateral rooms were added, one at the end of each lateral nave, and an apse was constructed. A marble schola cantorum with solea, existing also in the previous phases, was restored and improved. It was almost certainly richly decorated. At this point a doorway was also closed off (Figure 5). At the end of the sixth century the basilica was extended to the south. Two additional pairs of columns were constructed with Ionic capitals and a new façade, composed of an entrance decorated with a monumental triforium, two lateral entrances, and an external narthex (portico) regulating the access to the main building (Figure 6). The latter was not entirely excavated but was likely to have been composed of shorter columns and to have covered the width of the façade. It was previously considered as a "quadriportico" by Lanciani (1865), but the recent excavation rejected this. During the VIII century a hexagonal baptistery was added at the end of the western nave (Borrello et al 2002:1282). However, our study is limited only to the three phases in which the architecture and dates correspond to the notion of an Early-Christian basilica. In addition, our study has been limited to the evidence present in Paroli 2005. Additional interpretations are presented in (Borrello et al 2002) relating to, for example, the short and small triforiums in phase two, the postulated changing height of the schola in phase three, and the presence of polibolatis mosaic in the western nave. It was not possible to examine all of these in this paper but our work continues.

Roman building styles were adopted for the foundations and perimeter walls of the basilica, with Opus Latericium, Opus Vittatum and Reticulatum still appreciable in-situ. The church was constructed using the ancient Roman Foot and in its final form covered an area approximately of $20 \mathrm{~m}$. width and $45 \mathrm{~m}$. length, similar to the size of the plan of Saint Peter in Vincoli, Rome (Pensabene et al. 2007:461). The perimeter reused walls of earlier buildings or, as on the western side, common walls shared by other existing buildings. These have been interpreted as potential residential buildings, composed of two or more floors and probably used by the clergy. The ground plan of the Basilica Portuense is therefore unusual in the specifics, but conforms to the general structure of one larger and two smaller naves (Borello et al 2002: 1264). The two rows of columns are assumed on the basis of parallels to have supported arcades, hence raising the central ceiling above those of the lateral aisles. The pavement discovered shows different styles in use during the three phases. In the latest, the basilica was principally decorated with opus sectile all over the aisles. However, the building certainly incorporated archaic mosaics in the central nave, including one probably preserved by a postulated Early-Christian Ambon, and a pavement of bipedalis terracotta brick tiles decorated the northern half of the eastern aisle. In the clerestory, the remains of some furniture in marble were discovered, suggesting a central altar supported by four small columns and a cathedra surrounded by two semi-circular benches. These matched the shape of the apse and to be closed elegantly by two opposing dolphin armrests.

\section{Modelling the Basilica}

The foundations and flooring of the basilica are relatively well preserved. Therefore the main complexity in modelling the basilica arose from the elevations. Structural simulation using finite and discrete element analysis and other approaches was considered but for the purposes of this paper we have relied upon extensive discussions with the excavator Lidia Paroli, the architects, and on a wide range of parallel churches - in particular Sant'Agata dei Goti, Santa Sabina and San Vitale. 
We considered a wide range of factors in the construction and evaluation of the various models explored in this paper but here we will concentrate on those with a likely impact on visibility and lighting. The height and morphology of the roof was based on parallels but also on a detailed analysis of its potential construction. Modelling of multiple options was particularly important for the lateral naves where the wall line is irregular. The roof line in turn influenced the presence and shape of clerestory windows which have been informed by parallels and modified by the consequences of the lighting analyses described below. Similarly the windows in the apse are significant. Evaluation of Sant'Agata dei Goti and some structural details suggest that the Basilica Portuense may have had an unusual configuration of two large windows in the apse rather than the common three. Similarly it may be possible that there were smaller windows along the eastern aisle, similarly to those still viewable in the same Sant'Agata dei Goti or in Santa Sabina on the Aventine Hill in Rome. The buildings on the west make it unlikely that there were windows here. These two assumptions are also supported by the later construction of the triforium gate. Effectively, without this latter and without the windows described, the archaic lower part of the building was even darker during the day hours (see results below). Similarly the portico has an impact on the light entering the building, and the model of this was based in part on evidence at San Vitale in Rome.

Digital materials were generated in order to provide the necessary physical and aesthetic impact on the analyses described below. The marble of the capitals, the furniture in the apse, the schola cantorum and the ambon proved particularly challenging. Physically accurate materials were used as far as possible in order to represent some common Roman marble types including Lunense, Cipollino and Proconnesio. Where possible this was based on surviving materials but inevitably included a great deal of extrapolation form parallels. We were not able to undertake detailed microscopic analysis or gonio-reflectometry on fragments from the site. However, in part we have been able to use the knowledge of other marble fragments found at Portus and recorded using Reflectance Transformation Imaging. In addition to providing a colour calibrated dataset this technique also offers possibilities for representing the surface structure (via calculated normal) and hence the interaction with incident light (Earl et al 2010a; Earl et al 2010b).

Some material elements in the final model had to be based on photographs of the surviving and parallel datasets. It was not always possible to colour calibrate these and therefore the analyses for lighting sometimes used simplified, but physically accurate materials as a replacement. This is the case, for example, with a maritime mosaic and another mosaic representing black plaits excavated on the north-east side of the central nave. Similarly EarlyChristian mosaics preserved in the basilica of San Giovanni in Laterano were placed in the upper walls of the central nave of the Basilica Portuense, whilst the painting on the half dome derives from an original Early-Christian mosaic that existed on the half dome of Sant'Agata dei Goti. It was destroyed during a fire in the middle ages but had been represented in earlier drawings (Huelsen et al, 1924). As far as possible such imagery was used as a mask to enable physically accurate components to be used to calculate reflectivity. Indeed an attempt was made to synthesise the broad spectrum of pigments contained in such paintings via a simple geometric material that matched their proportions but not their distribution. Thus, in the final renderings an attempt was made to use the locations of these paintings and their broad colours to add appropriate reflected colour to the scene rather than as particular points of interest. Final dressing of the model included addition of curtains and artificial luminaires. These were generally kept very simple, with the intention of adding an indication and having an impact on lighting. However, the large chandeliers are based on discussions with the excavator and other experts, and on studies of similar Early-Christian luminaires. 


\section{Uncertainties in the morphology of the Basilica as modelled}

Whilst it is important to identify uncertainties in computer simulation, the definition of a precise series of options can lead to a reduced awareness of the plethora of additional uncertainties. Computer modelling is inevitably a hybrid of art and science: it is a process of informed extrapolation, in a social, cultural and methodological context. However, as this paper considers formal analyses that are themselves solely based on these simulations, we have attempted to systematise the uncertainties, at least as they are perceived by us and the others involved in the research. The previous sections have outlined a range of uncertainties in terms of morphology, material and illumination. In addition to a host of others we considered the following uncertainties in some detail in the manual and procedural modelling approaches employed:

- Façade from phase two

- Location of windows in the nave, apse and eastern aisle in phases one, two and three

- Morphology of the portico in phase three

- Morphology of the postulated ambon

- Exact height of the schola cantorum

- Remains of the benches and altar were excavated but uncertainties of their original form

- Structure of the roof trusses

- Uncertain longitudinal wall in phase one

- Opus sectile and bipedalis are poorly preserved but indicated by the surviving impressions. As opus sectile re-uses polychromatic pieces the specific types will have an impact on the reflected light within the scene.

- Several possible arrangements for the pavement in the central nave

- Decoration of the walls; only limited surviving fragments of painted plaster

\section{Formal Analyses of the Basilica Portuense}

\section{Uncertainty and Procedural Modelling}

The uncertainties inherent in the simulation of past environments from data of variable quality is at the core of critiques of computer graphic modelling in cultural heritage. The issues surrounding authenticity, and potential means to demonstrate uncertainty have been covered in very considerable depth elsewhere. For this study we concentrate on means to introduce uncertainty into formal analyses. In the context of visibility-based studies we have considered the possibilities of manual variation in model parameters in order to conduct sensitivity analyses of a form associated with landscape viewshed analysis (Paliou et al; see also Paliou and Wheatley 2007). The potential of procedural modelling techniques for demonstrating ambiguity is beginning to be realised, particularly as technologies such as CityEngine have emerged (Haegler et al 2009; Müller et al 2007). CityEngine uses the CGA shape grammar (Müller et al 2006; Wonka et al 2003) in order to define partitioned geometry. Other approaches such as that defined by Merrell (2007) provide alternative methods for parameterising model construction. 
In this paper we advance the use of the same procedural approaches to produce variation in geometry prior to formal calculation of visibility or lighting. By scripting stochastic parameters the interpretation necessarily requires a clear understanding of the uncertainties in the data and their interpretation, but in return enables very rapid numbers of variations to be produced. In turn the formal analyses undertaken can be based on a larger, more statistically significant population. Such techniques are not seen as enhancing the quality of given modelled outputs, but rather as a means to characterise the certainty surrounding them. In lighting and rendering this stochastic component is essential. As we have identified above not only must we consider structurally constrained parameters such as the location and size of windows, but also the possibilities of furniture such as screens and benches, and the properties of artificial luminaires.

For the purposes of this paper we used the procedural modelling capabilities to define variation in the size and shape of the clerestory windows, within parameters specified on the basis of surviving basilicas. First a sample of ten permutations for the clerestorey was generated using CityEngine. Figure 7 shows the variation in the stochastic meshes produced. These were then compared as part of the lighting analysis described below. Many more permutations were used to examine the visibility of the areas in the clerestorey where decorated panels are postulated.

\section{Texture Viewsheds}

In 2005 we introduced the Texture Viewsheds method (Earl 2005). This used a moving light source to produce patterns of light on surfaces within three-dimensional models, corresponding to lines of sight. The technique allowed the summarising of spaces according to relative visibility, angle of visibility, and distance of viewer from the point viewed. In turn visibility maps for the spaces summarised were used to define automated pathways through those spaces, optimising visibility of particular areas. In this way it was possible to produce simulated pathways potentially corresponding to deliberate design. The obverse technique summarised the visual experience given a particular path through space. The numeric summaries produced through this method included the cumulative visibility of surfaces from all view points and an indication of the area of a given space or sub-space visible from particular observer locations. Through this technique it was possible to produce summaries that were hypothesised to parallel subjective appraisals of concepts such as enclosure.

In our revised implementation of Texture Viewsheds for this paper we employ the rasterbased methodology outlined above only as a means to produce targeted fine-grained coverages. We use the VIPS framework (Martinez and Cupitt 2005; Cupitt and Martinez 1996) to produce the graphical summaries. The sample resolution and hence the spatial precision of the raster approach is limited only by the chosen output raster and the size of the unwrapped geometric component. Figures 8 and 9 shows some sample Texture Viewshed outputs from this technique

Given the computational overheads required for a full Texture Viewshed coverage at high resolution this paper introduces an additional approach that uses only the modelled geometry. This latest method is undertaken entirely in 3ds Max, using MaxScript to obtain a summary of visible vertices. Post-processing of these data in a database enables outputs of summary statistics such as angle of view, surface normal of viewed location, distance between observer and viewed location, angle of view in $\mathrm{XY}$ and $\mathrm{XZ}$ planes, visibility by surface areas, cumulative and probabilistic visibility. These are then in turn reloaded to the scene in order to produce a visual representation of patterns of visibility in the modelled scene. In terms of previous work this is closest to that proposed by Engel and Döllner (2009). Our contribution is to implement the system in a parallel environment to other analyses, employing the same 
geometry (i.e. 3ds Max Design 2011) and to allow the rapid computation of summary statistics conforming to extant archaeological and more general spatial interpretation. Also in combination with the approach advanced in 2005 we are able to produce extremely high resolution surface visibility metrics that are impractical using a geometric approach. Finally, we produce summaries of surface visibility values in addition to the identification of viewer statistics mapped onto their locations.

The modelled scene is prepared as for the standard Texture Viewshed approach. A watertight mesh is generated with no overlapping surfaces. Each surface is then subdivided to produce an approximate equal mesh density across the model. This allows for general comparisons to be made in terms of relative visible areas. Such subdivision can be done relatively easily at the end of the modelling stage. In addition, a maximum size of face can be generated by projecting a vector shape grid onto each modelled object. As a check Max Script allows any faces outside of a given area threshold to be identified. In some cases it may be preferable to generate high density sample regions in order to examine particular areas in detail. This invalidates any visibility density summaries however. Alternatively the area of the surface can be compared to the proportion of the total number of vertices that is visible.

A voxel data representation is then approximated within the scene by stacked planar geometry where the separation of the geometry matches that of the gridded planes (Figure 10). These slices in turn are used to iterate through viewer positions by moving a light source to each vertex in turn. This enables the rapid creation of a voxel representing the open area in a space within which observers can move. Having generated the visibility statistics (Table 1) the geometry is remapped via vertex colours to represent the chosen pattern of visibility (Figure 11). The remapped model can then be explored interactively.

The simplified Basilica Portuense model analysed contains approximately 9,500 model vertices. The visibility of each vertex was tested against one of 1656 observer locations. The observers were defined by a $1 \mathrm{~m} \times 0.5 \mathrm{~m}$ voxel representation three layers thick - sampling visibility throughout the building at observer heights of $1 \mathrm{~m}, 1.5 \mathrm{~m}$ and $2 \mathrm{~m}$. Visibility data were then remapped to the model surfaces. The analysis time on a standard specification 64bit $2.67 \mathrm{GHz}$ dual core system with $4 \mathrm{~GB}$ Ram is approximately 0.14 seconds per vertex per observer. As a consequence we used the University of Southampton Iridis3 supercomputer to enable the analysis to be completed on up to 30 dual quad core $2.27 \mathrm{GHz}$ nodes in less than a day. We explore the results of these techniques below.

\section{Lighting Analysis}

The lighting analyses conducted in 3ds Max Design 2011 of the Basilica Portuense started by creating a daylight system and defining the exact coordinates for the subject matter: N41.77, E. 12.26. The scene was checked for invalid lights and materials, according to the requirements identified above, and frame buffer set to floating point. Similarly, optimal settings were chosen for the simulation of light energy within the scene. The mr Physical Sky was used as an environment shader, with CIE Clear Sky used as a sky model to define the typical brightness distribution of the skylight. The tested date was 20th March 2011 with samples at $9 \mathrm{am}, 1 \mathrm{pm}$ and $5 \mathrm{pm}$. While precise ephemeris data exist and have been employed elsewhere to guarantee sun angles (e.g. Papadopoulos \& Earl 2009) we do not judge them to have had a sufficient impact in this case, particularly given the broad time samples examined.

The results are expressed in three ways: rendered image overlay, pseudo-colour exposure control and lighting meters. These were produced for all the structural models tested as well as the different times during the day. The pseudo-colour and the rendered image overlay are view dependent, which means that the values obtained illustrate the amount of energy returning to the camera. For both pseudo-colour and image overlay, the results were delivered 
in Luminance $(\mathrm{cd} / \mathrm{m} 2)$, indicating how much luminous power will be perceived by an eye looking at the surface from a particular angle of view. It is thus an indicator of how bright the surface will appear. On the other hand, the light meters, which only measure Illuminance (lux) are view independent and thus depict the intensity to which something is illuminated respecting the physical qualities of the objects.

A range of modifications were made to the master model of the Basilica Portuense in order to examine the impact that the contribution of light might have at the interior. The primary model of the Basilica was modelled with several doors, for which the height is uncertain, while the triforium has been simulated with three curtains, the middle of which, is semi-open. In order to test all the possible options for the amount of light that entered to the interior, it was decided to render additional structural models with less or no curtains and some or all of the doors open. Besides, lighting analysis was undertaken on a variation with four windows at the east side of the building (Figures 12 and 13). As there are several reasons why windows at the other sides of the buildings are not structurally possible, and are mainly related to the existence of other structures in contact to the Basilica, it was decided not to produce and test more structural models with windows at the other sides as well. The other buildings attached on the western side existed at least since the beginning of the third century and were at least two storeys high, covering the entire height of the western walls of the basilica. In addition, the ten variants of the clerestory windows described above were tested to see if they might have resulted in any different impact on the amount of light entered to the interior. The alternative models of the clerestory windows deliberately do not include glass or frames in order that the impact of the geometry alone could be isolated. Therefore the specific energy values are not discussed (since these are related to the transmission and other properties of the glass), but rather the relative impact of the morphological changes on the light entering the space. In a future study we will undertake a more detailed sensitivity analysis, using physically accurate glass parameters from the period. Still, taking into account the clerestory modifications described above, a total of 160 individual model permutations were considered in this lighting study.

The results of these analyses demonstrate that the contribution of light in the interior during the whole day is quite significant, while the amount of light linearly decreases as it reaches the floor of the Basilica (Figure 14). A great amount of light is accumulated at the upper part of the structure where the clerestory windows exist (Figure 15). Light also enters through the open side-doors, and the windows of the sanctuary at the lower part. To be more specific, the amount of light reaching the floor does not exceed $5-10 \mathrm{~cd} / \mathrm{m} 2$ during the day, whereas at the upper parts of the nave the values are dramatically increased because of the windows, in several cases exceeding $1000 \mathrm{~cd} / \mathrm{m} 2$. Though in several areas, usually near closed doors or where no openings exist the values are considerably low. On the other hand, at the areas where side openings have been modelled the values increase reaching $40-60 \mathrm{~cd} / \mathrm{m} 2$ and gradually decreasing (Figure 16), not having a great impact to the nave of the Basilica. In general it can be argued that the amount of light up to the human height is noticeably low during the whole day, while it slightly increases when light shafts directly affect the interior. On the other hand, the upper part is well illuminated during the day and any existing paintings should have been equally illuminated as well. The narthex is always over-lit as it belongs to the exterior of the Basilica and comprises a transitional area to the interior.

Certain areas of the Basilica remain under-lit or over-lit during the day, which may have been related to ceremonial practice (Figure 15). For example, the sanctuary seems to be lit only by the two windows modelled at that area, while any light coming from the clerestory, any sideopenings and the triforium seem not to significantly affect its illumination (Figure 15). In any case, there is a variety in the obtained values, with higher levels in the morning and early 
afternoon, and lower values in the evening. The triforium is less illuminated in contrast to other areas at the nave of the building, apart from the time of the day when light beams enter through the windows of the apse. In considering this we cannot wholly reject the possibility of windows covered with curtains, although the function of the building, the location of the building relative to surrounding buildings, and their arched form all suggest they were unlikely. The ambon seems to be well illuminated during the whole day, mainly because of the light coming from the clerestory windows (Figure 16).

The fact that a low amount of light reaches the floor suggests that mosaics and the opus sectile floor were not well illuminated with the exception of any light rays coming from the clerestory and the triforium. The physical properties of these floors have been investigated in detail and such isolated pools of light would have created colourful and potentially sparkling variations (Figure 17). It was also observed that the greater impact of light in the interior is attested when the sun is at specific angle, i.e. in the morning hours (9-11am) and late afternoon $(2-5 \mathrm{pm})$, significantly affecting both the illumination of the building and also producing a series of effects (e.g. reflections) as the light interacts with the materials used for the columns and the other marble elements (Figure 18).

The tested variations, namely no curtains at the narthex, all the curtains closed and all the doors open resulted in great variations in the lighting values obtained. For example, a model with the curtains closed produced lower lighting values at the nave and even lower at the aisles (Figure 19). These values range from $10-50 \mathrm{~cd} / \mathrm{m} 2$ in morning hours, while the areas where rays of light come through the side doors or other openings produced values ranging from $50-120 \mathrm{~cd} / \mathrm{m} 2$, exceeding that amount toward the midday. The values at the upper part of the nave walls (clerestory) remained stable, as the lighting at that part is dependent on the clerestory windows. In phase three when the curtains are open at the triforium the light entering from the exterior passing through the exonarthex is significantly increased, while the values are even higher during the afternoon. On the other hand, when the model is rendered with the curtains and the side doors open, the values obtained considerably increase (Figure 20). The greatest part of the nave is well illuminated, while the values linearly decrease as the rays of light reach the sanctuary. Similarly the aisles are better illuminated with values exceeding $1000 \mathrm{~cd} / \mathrm{m} 2$ at the front part of the Basilica. The great amount of light coming from the various openings significantly affects the illumination of the whole building producing values atypical for such environments. The aisles of the Basilica, especially toward the sanctuary are significantly dim. However, the alternative model with the four windows at the east side produced higher values at that area, also partly affecting the illumination of the nave (Figure 21). The highest values were observed in the morning hours, while the light gradually decreases toward the evening; though it cannot be argued that they have a significant impact on the overall illumination of the Basilica.

The procedural clerestory variations were tested with light meters to observe the light differences, concentrating in the upper parts of the Basilica where there is likely to be most impact. As can be observed in the table below (Table 2) each structural variation resulted in higher or lower amounts of light entering the interior. The difference between model iterations 2 and 3 as well as 7 and 8 is negligible, whilst the difference between 3 and 4 or 6 and 7 is more than $150 \%$. The latter disparity is mainly due to the greatest difference in the dimensions of the windows. Overall the minimum 40.8 lux and maximum 212 lux values represent a maximum variation of more than 500\%. Per pixel comparisons of the type outlined may inevitably be biased by discrete factors however. For example, a slight change in window size may result in a sufficient angular variation to allow in direct light from the luminaire. We therefore need to undertake addition work to validate and cross check the results with other lighting analysis methods and to assess variations across wider areas. Still, 
this comparative study proves that the way that light interacts in an environment as well as the visual effects produced highly depend on the architecture of that environment and even slight changes can result in different outcomes (see also Papadopoulos \& Earl forthcoming; Papadopoulos 2010).

\section{Informal Appraisal of the Constructed Basilica Portuense}

The final means of engagement with the modelled Basilica Portuense was through the many alternative rendered outputs generated. This paper identifies only a tiny fraction of the many hundreds of rendered scenes and objects produced in the writing of this paper, and throughout the modelling of the Basilica. Indeed creation of rendered outputs frequently led to a rethinking of the formal approaches and their results. The process of researching, creating and visually experiencing these modelled environments was profound, and provided an extremely detailed appraisal both of the site as known and the great extent both to which it can be reconstructed and will remain unobtainable. The influence of the modelling process is evidenced throughout the conclusions outlined below.

\section{Conclusions}

The roles of changing visibility and the interaction of light with surfaces within religious structures is clearly complex, variable and frequently unobtainable in archaeological contexts. Contemporary and recent ethnographies highlight the significance of light in defining spatial behaviour and practice in religious spaces, whilst alignments and statistically significant variations in the pattern of light and shade in older religious spaces implies a significance to illumination in devotion. In a Roman setting Vitruvius spoke specifically about the impact of light on buildings. Ecclesiastical texts and philosophy, and also architecture suggest but do not prove builders' consideration both of the functional and mental role of light. Furthermore, the relationship between building morphology, orientation, lighting, decoration and practice is sufficiently complex and indeterminately interdependent that categorical statements elude us. Nonetheless, a significant amount of work has been undertaken regarding the discussion of illumination and especially of its visual effects in religious architecture (for example see Whittemore 1933: 12-28, Krautheimer 1965: 153-159), investigating the impact to the believers by evoking poetic embodiments of place enhancing the religious experience.

Comparatively fewer projects have worked toward the estimation of light in such contexts examining the atmosphere of religious architecture which to a great extent owes that intangible quality to an intentional manipulation of light for evocative purposes. One of the most prominent examples of such work is Potamianos $(1996,2002)$, who talked about the close relation of light to architecture by observing a series of Byzantine churches and comparing their orientation and size as well as number and dimension of openings, trying to talk about the importance of light from a historical and empirical point of view. Additionally, Antonakaki (2007) has attempted a comparative study of a church and an Ottoman mosque talking about the spatial relation between the believers and the buildings. An earlier attempt was made by Triantafyllides (1964), who tried to estimate the amount of light in churches by using a light meter at specific locations, although the results were not related to any liturgical events. Unver and Enarun (1999) have provided a set of proposed illumination quantity and quality for specific areas in churches, while Liritzis and Vassiliou (2007) have undertaken a preliminary investigation regarding the orientation of Byzantine churches in relation to the solstices and equinoxes as well as the name day of the saint. Lastly, there are a few case studies that examine the illumination in buildings with special architectural characteristics, sculpture, frescoes and monumental art (see for example Iliadis 2001, 2005). 
In our own case study we have deliberately explored the full range of archaeological uncertainties in order to problematise and evaluate some formal modes of analysis. Given the range of variables, and the numerous lighting and structural models that can be produced on the basis of their ambiguities, we would propose that however sophisticated the models available the resulting conclusions must be vague and clearly qualified. This analysis can only ever provide one input to the various approaches employed in archaeological interpretation. Still, allowing for the considerable flexibility in the models produced our findings do propose a number of points for consideration. The distribution of light to the interior is not uniform in any of the model permutations, and the arrangement of the Basilica in zones (exonarthex, nave, aisles and sanctuary) goes with the distribution of the illumination and visibility creating a blending space (Antonakaki 2007: 057-11). The daylight levels observed are relatively low at the lower part, which is linked to the human presence, while the upper area is well lit because of the clerestory windows, perhaps accounting for the dwelling of God. The hypothesised area of paintings is also very prominent (Figure 22), with the sections at either end particularly prominent in terms of angle of view (Figure 23).

The lighting and visibility analyses clearly demonstrate that the main visual focus is the main axis, while the most visually integrated area is the centre of the church, at the point where the Ambon is located. The aesthetic impression of the church is primarily enhanced by the movement from the entrance to the sanctuary (Kalligas 1946), while the light is concentrated in specific areas to direct the eye movement and indicate where the interest in space should be focussed (Potamianos 1996: 154). On the other hand, the aisles which have a secondary role in the church employ much lower values as an indication of that (Davies 1985: 95). The texture viewsheds analysis demonstrates a significant reduction in visibility of the aisles, particularly at human height. However, the first and the last attraction is towards the light coming from the top, which is apparent especially in domed churches, as that is the point that the members of the congregation should reach according to the dogma. Presumably the overall aesthetic would have been enhanced not only by the vision and the interplay of light and shadows, but also through the rest of the senses, when listening to the priests, the echoes and the resonance of steps, as well as when smelling the burning of incense and the candles.

When moving along the main axis of the church, a series of transitions becomes apparent mainly occurring with a decrease in light, supported by the visibility results. The initial transition from the exterior to the exonarthex is evident with a slight decrease in light, which in turn provides the illusion of a rite of passage to the interior of the church, where the light is significantly less. Through this transition, the subject is gradually adapted to the less lit interior, while seeking sources of light as an orientation factor. At this point, the church is revealed through darkness on light with the shades playing an important role being in constant motion delineating three-dimensional forms (Davies 1982: 95). However, the light coming from different directions minimises the strong directional shadows, therefore assigning a symmetrical balance to the space. This lack of light in conjunction with the darker areas perhaps evoked mystical feelings and devoutness (Antonakaki 2007: 057-06), while the fact that certain parts are illuminated differently, may indicate a symbolic and gradual transition to areas of higher sacredness (Humphrey and Vitebsky 1997).

The Basilica is dominated by light from the clerestory windows, which might have been intensified by the use of translucent glass is reflected on the various specular surfaces also creating clouds of light and other atmospheric effects (Figure 25). In addition, the various polychrome surfaces and mainly the marbles would have created a bleeding effect producing random or even intentional coloured animations of the interior space. The use of flame illumination cannot be excluded (Figure 26), and actually should be emphasised as it might have provided more light both for the common practices and the various rituals, therefore 
serving a functional and symbolic role, contributing to the enhancement of the religious atmosphere adding a sense of mystery and devotion. Whilst we have employed such artificial luminaires in our rendering work we plan to include it in formal lighting analysis at a later stage of the project.

As mentioned previously, this integrated analysis can only provide an indication of the various methodological tools that can be employed in the reasoning process attempting an enhanced archaeological interpretation. The various constraints that the dataset poses and the numerous lighting and structural models that can be produced occasioned by the ambiguities of the records, cannot directly prove the answers to research questions. The Basilica Portuense remains a complex visual space, and our engagement with it has been a selfconsciously ocularcentric one. It has been our attempt in this paper to identify vision-specific methods for exploring the Basilica in a way that as far as possible relates to the physical possibilities of the imagined original place. In this work we have not ignored the possibilities of alternative sensoriums however and indeed, as our work continues we look forward to an increasingly multi-sensory exploration of the Basilica. Already the possibilities of technologies such as acoustic rendering are clear. Whatever we can add to the vitality of the engagement with the modelled past must surely assist in our living in the modelled world - in gaining a sense of presence (Ch'ng, 2009) - as a means to try to understand it in new ways.

In the context of much more recent religious spaces Giles has made clear the extent to which they were places of memory, and thus potentially places as much about what could no longer be seen, what had been covered over or destroyed, as places to be seen (2007:115). She also outlines the importance of movement, supporting our own emphasis on unfolding visual narratives in the visualised and analysed spaces of the Basilica.

\begin{abstract}
"From the late fourteenth century onwards, changes in liturgy and architecture made the rite of the Mass less physically accessible to the laity. In response, an increasing emphasis was therefore placed on medieval seeing as a means of participating, visually and bodily, in the divine... Traditionally, archaeologists have modelled these lines of sight as straight lines (Graves 2000; Roffey 2004). Yet perhaps we need to take more account of the circuitous journeys and movements that this seeing involved: negotiating or pushing one's way through the crowd, peering around tombs or other monuments, jostling for a glimpse through the squint or hagioscope and kneeling, stooping, stretching, craning and straining to see and hear the moment of the elevation of the Host, signalled by the ringing of the sacring bell." (Giles 2007: 115)
\end{abstract}

We believe that in creating the Basilica Portuense to explore again we are enabling such circuitous journeys to be recreated, to generate serendipitous discoveries of places and objects and to come to some sense of the religious through the lens of crumbled walls, fragmentary mosaics and computer wireframes. As our research continues we look forward to peopling our models, not merely in the sense of adding the human form to the sterile landscape, but as agents in its rediscovery.

\title{
Acknowledgements
}

This work would have been impossible without the knowledge, advice and enthusiasm for the site exhibited by Dr Lidia Paroli. We are also very grateful for the support in Italy from Dr Roberta Loreti, Dr Giuliana Irace, Dr. Luciana Borrello, Dr Anna Lucia Lionetti and Dr Mauro Maiorano.

The technical and analytical work has been much improved through discussions with and help from Kirk Martinez, John Cupitt, Procedural Inc., Tom Frankland, David Wheatley, and the Microsoft Institute for HPC. Eleftheria Paliou has been a constant source of inspiration and animated discussion. 
The research was supported by the UK Arts and Humanities Research Council via the Portus Project, the Portus in the Roman Mediterranean Project and the Reflectance Transformation Imaging System for Ancient Document Artefacts Project.

\section{References}

Allison, P M. 2001. Using the Material and Written Sources: Turn of the Millennium Approaches to Roman Domestic Space. American Journal of Archaeology, Vol. 105, No. 2. (April, 2001), pp. 181-208.

Antonakaki, T. 2007. Lighting and Spatial Structure in Religious Architecture, a Comparative Study of a Byzantine Church and an Early Ottoman Mosque in the City of Thessaloniki. Proceedings of the 6th International Space Syntax Symposium. 057, 01-14.

Beale, G., Earl, G.P., Chalmers, A., Happa, J. and Williams, M. 2010. Polychromy, Digital Simulation and an Amazon from Herculaneum, In: A. Moore, A., G. Taylor, E. Harris, P. Girdwood, L. Shipley (eds), Conference Proceedings, TRAC 2009.

Benedikt, M.L. 1979. To take hold of space: isovist fields, in Environment and Planning B: Planning and Design, vol. 6, pp. 47-65, 1979.

Bertille Robin, Thibaut Hilpert, Keisuke Miyazawa, Patrick Callet, François-Xavier de Contencin and Anna Zymla 2010, Virtual Replication of the Idalion Tablet. VAST 2010. 1710

Blomberg, M. \& Henriksson, G. 2002. Literary and Archaeoastronomical Evidence for the Origins of the Hellenic Calendar in the Aegean Bronze Age, in: A. Maravelia, (ed.), Ad Astra per Aspera et per Ludum European Archaeoastronomy and the Orientation of the Monuments in the Mediterranean Basin, Thessaloniki.

Borrello, L., Maiorano, M., Paroli, L., Serlorenzi, M. 2002. La basilica urbana di Porto, in F. Guidobaldi, A. Guiglia Guidobaldi (a cura di), Ecclesiae Urbis, Atti del Congresso Internazionale di studi sulle chiese di Roma (IV-X secolo) (Roma, 4- 10 settembre 2000), Roma 2002, pp. 1263-1285.

Boyce, R. P. 2003. Human Factors in Lighting, USA, Taylor \& Francis.

Callet, P. Dumazet, S., Leclercq, C. and C. Politi 2010. Natural Lighting, Gilts and Polychromy of Notre-Dame de Paris Cathedral. In: A. Artusi, M. Joly-Parvex, G. Lucet, A. Ribes, and D. Pitzalis (eds), Conference Proceedings, 11th VAST International Symposium on Virtual Reality, Archaeology and Cultural Heritage, 63-70.

Chalmers, A., Roussos, I., Ledda, P.: Authentic illumination of archaeological site reconstructions. In CGIV'2006: IS\&T's Third European Conference on Color in Graphics, Imaging and Vision (2006).

Chalmers, A \& Zányi, E. 2009. Real Virtuality: Emerging Technology for Virtually Recreating Reality, in: Becta, http://www.becta.org.uk.

Chalmers, A.G., Debattista, K., Mastoropoulou, G. and dos Santos, LP. 2007. There reality: Selective rendering in high fidelity virtual environments". International Journal of Virtual Reality, vol 6, no 1.

Chalmers, A. 2002. Very Realistic Graphics for Visualising Archaeological Site Reconstructions, In: Conference Proceedings, 18th spring conference on Computer graphics, ACM Press, New York, 7-12. 
Clark, D.L. 2007a. Public and Private Space at Deir 'Ain 'Abata: an application of Space Syntax Analysis to the monastery. In K. D. Politis (ed.). Excavations at the Sanctuary of St. Lot, Deir 'Ain 'Abata, Jordan. 1998--2003. London: British Museum Press.

Clark, D.L. 2007b. Viewing the liturgy: A space syntax study of changing visibility and accessibility in the development of the Byzantine church in Jordan .World Archaeology. Vol 39.1. 84-104.

Classen, C. 1993. Worlds of Sense: Exploring the Senses in History and Across Cultures, London, Routledge.

Cupitt, J and Martinez, K. (1996), „VIPS: An Image Processing System for Large Images“, in: Conference Proceedings, IS\&T/SPIE Symposium. Electronic Imaging: Science and Technology, 2663, Very High Resolution and Quality Imaging, 1996, 19-28.

CURET. Columbia-Utrech Reflectance and Texture. Web page. http://www.cs.columbia.edu/ CAVE/curet/.

Dana, K. J., Van Ginneken, B., Nayar, S. K., and Koenderink, J. J. 1999. Reflectance and texture of real world surfaces. ACM Transactions on Graphics 1, 18, 1-34.

Davies, J. G. 1982. Temples, Churches and Mosques: A guide to the Appreciation of Religious Architecture. Oxford.

Dawson, P. \& Levy, R. 2005. Explore the Ideological Dimensions of Thule Whalebone Architecture in Arctic Canada, in Internet Archaeology, 18:1, 2005. http://intarch.ac.uk/journal/issue18/

Dawson, P., Levy, R., Gardner, D. and Walls, M. 2007. Simulating the Behaviour of Light Inside Arctic Dwellings: Implications for Assessing the Role of Vision in Task Performance, in: World Archaeology, 39, 1, 17-35.

De Rossi, G.B. 1866. Bullettino d'archeologia cristiana, IV, 6, p.99-100

Devlin, K. \& Chalmers, A. 2001. Realistic Visualisation of the Pompeii Frescoes, in: A. Chalmers and V. Lalioti (eds), Conference Proceedings, 1st international conference on Computer graphics, virtual reality and visualisation, AFRIGRAPH 2001, ACM Press, 43-47.

Devlin, K., Chalmers, A., Brown, D. 2002. Predictive Lighting and Perception in Archaeological Representations, in: Conference Proceedings, UNESCO World Heritage in the Digital Age, 30th Anniversary Digital Congress.

Dobbins, J. \& Gruber, E. (forthcoming), „Illuminating Historical Architecture: The House of the Drinking Contest at Antioch", in: F. Contreras and F. J. Melero, Conference Proceedings, XXXVIII Computer Applications \& Quantitative Methods in Archaeology 2010.

Dobbins, J. \& Gruber, E. (forthcoming) Modeling Hypotheses in Pompeian Archaeology: The House of the Faun, in: F. Contreras and F. J. Melero, Conference Proceedings, XXXVIII Computer Applications \& Quantitative Methods in Archaeology 2010.

Earl, G., Cox, G., Cox, S., Frankland, T., Parchment, O., Takeda, K. and Thorne, S. (forthcoming b) High Performance Computing and the Construction of Archaeological Computer Graphic Simulations, in: Conference Proceedings, XXXIX Computer Applications \& Quantitative Methods in Archaeology 2011.

Earl, G.P., Beale, G., Martinez, K. and Pagi, H. 2010. Polynomial texture mapping and related imaging technologies for the recording, analysis and presentation of archaeological materials. In, ISPRS Commission V Midterm Symposium, Newcastle, UK 
Earl, G.P., Keay, S.J. and Beale, G. In Press. Archaeological Computing for Recording and Presentation of Roman Portus, in: S.J. Keay, and L. Paroli (eds), Workshop Proceedings, The First Portus Workshop, Rome, March 2008, British School at Rome Monographs.

Earl, G.P., Martinez, K. and Malzbender, T. 2010. Archaeological Applications of Polynomial Texture Mapping: Analysis, Conservation and Representation. Journal Archaeological Science 37

Engel, Juri and Döllner, Jürgen 2009. Approaches Towards Visual 3D Analysis for Digital Landscapes and Its Applications. Digital Landscape Architecture Proceedings 2009, pp. 3341, 2009.

Eugene Ch'ng, 2009. Experiential archaeology: Is virtual time travel possible?, Journal of Cultural Heritage, Volume 10, Issue 4, October-December 2009, Pages 458-470,

Fevrier 1958 Ostie et Porto à la fin de l'Antiquité : topographie religieuse et vie sociale. MEFRA, 70, Pages 295-330.

Fiocchi Nicolai, V. 2001. Strutture funerarie ed edifici di culto paleocristiani di Roma dal IV al VI secolo: Pontificia Comm. Arch.Sacra.

Garg, K. and Nayar, S.K., 2006. Photorealistic rendering of rain streaks. ACM Transactions on Graphics, 25(3), p.996.

Giles, Kate. 2007. Seeing and believing: visuality and space in pre-modern England. World Archaeology, Volume 39, Number 1, March 2007 , pp. 105-121(17)

Goodison, L. 2001. From Tholos Tomb to Throne Room: Perceptions of the Sun in Minoan Ritual, in: R. Laffineur, \& R. Hägg, (eds) Conference Proceedings, Aegaeum 22 POTNIA, Deities and Religion in the Aegean Bronze Age, The 8th International Aegean Conference.

Gutierrez, D., Sundstedt, V., Gomez, F., Chalmers, A. 2008. Modeling light scattering for virtual heritage. Journal on Computing and Cultural Heritage.

Haegler, S., Müller, P. and Van Gool, L. 2009. Procedural Modeling for Digital Cultural Heritage“", in: EURASIP Journal on Image and Video Processing, 2009.

Happa J, Artusi A, Czanner S, Chalmers A. 2010. High Dynamic Range Video for Cultural Heritage Documentation and Experimental Archaeology. VAST10: The 11th International Symposium on Virtual Reality, Archaeology and Intelligent Cultural Heritage. Full Papers:17-24.

Happa, J., Williams, M., Turley, G., Earl, G. P., Dubla, P., Beale, G., Gibbons, G., Debattista, K., Chalmers, A. 2009. Virtual relighting of a roman statue head from herculaneum: a case study. In AFRIGRAPH '09: Proceedings of the 6th International Conference on Computer Graphics, Virtual Reality, Visualisation and Interaction in Africa (2009).

Happa, J. et al 2009a. The Virtual Reconstruction and Daylight Illumination of the Panagia Angeloktisti, in: K. Debattista, C. Perlingieri, D. Pitzalis, and S. Spina (eds), Conference Proceedings, 10th VAST International Symposium on Virtual Reality, Archaeology and Cultural Heritage 2009.

Happa, J. et al. 2009b. Illuminating the Past - State of the Art, in: K. Debattista, C. Perlingieri, D. Pitzalis, and S. Spina (eds), Conference Proceedings, 10th VAST International Symposium on Virtual Reality, Archaeology and Cultural Heritage 2009.

Hašan, M. et al., 2010. Physical reproduction of materials with specified subsurface scattering, New York, New York, USA: ACM Press. 
Hasic, J., Chalmers, A. and Sikudova, E., 2010. Perceptually guided high-fidelity rendering exploiting movement bias in visual attention. ACM Transactions on Applied Perception, 8(1), pp.1-19.

Hašan, M., Fuchs, M., Matusi, W. and Rusinkiewicz, S. 2010. Physical reproduction of materials with specified subsurface scattering. ACM Transactions on Graphics 29(4). Article $61: 1-10$

Hawkins, T., Einarsson, P. and Debevec, P., 2005. Acquisition of time-varying participating media, New York, New York, USA: ACM Press.

Huelsen, C., C. Cecchelli, G. Giovannoni, U. Monneret de Villard and A. Munoz. 1924. Monografie sulle chiese di Roma, Sant'Agata dei Goti. Rome.

Humphrey, C. and Vitebsky, P. 1997. Sacred Architecture. Boston: Little Brown \& Co.

Iliades, I. 2005. 'The Natural Lighting in the Dome of Rotunda at Thessaloniki' In Lighting Research and Technology. 37. 183-198.

Iliadis I. 2001. The Natural Lighting of the Mosaics in the Rotunda at Thessaloniki In Lighting Research and Technology. 33. 13-24.

Jay, M. 1996. Vision in Context: Reflections and Refractions, in: T. Brennan, M. Jay (eds), Vision in Context: Historical and Contemporary Perspectives on Sight, London, Routledge.

Kalligas, M. 1946. H Aisthitiki tou Horou tis Ellinikis Ekklhsias sto Mesaiona (The aesthetics of Greek Church in Medieval Times - in Greek). Athens

Keay, S., Millet, M., Paroli, L. and K. Strutt. 2005. The Portus Project. London: Archaeological Monographs of the British School at Rome.

Kider, J. T., Fletcher, R. L., Yu N., Holod, R., Chalmers, A., Badler, N. I.: Recreating early islamic glass lamp lighting. In VAST '09: Proceedings of the Symposium on Virtual Reality, Archaeology and Cultural Heritage (2009).

Krautheimer, R. 1965. Early Christian and Byzantine Architecture. Baltimore: Penguin Books

L. Wang, L. Z., T. Fang, X. Yang, X. Yu and S.B. Kang, Real-Time Rendering of Realistic Rain, Microsoft Research, Microsoft Corporation, 2006.

Lanciani R. 1866, Lo Xenodochio di Pammachio in Porto, BACrist 4, 99-103

Lanciani, R. 1865. Ricerche topografiche sulla città di Porto. Rome.

Ledda, P., Santos, L. P., Chalmers, A.: A local model of eye adaptation for high dynamic range images. In AFRIGRAPH '04: Proceedings of the 3rd international conference on Computer graphics, virtual reality, visualisation and interaction in Africa (2004).

Liritzis, I. and Vassiliou, H. 1997. Does Sunrise Day Correlate with Eastern Orientation of Byzantine Churches on Significant Solar Dates and Saint's Days? A Preliminary Study. In Byzantinische Zeitschrift. 99.2. 523-534.

Lock, G. 2003. Using computers in archaeology: towards virtual pasts. Routledge, London

MacGregor, C. 1999. Making Sense of the Past in the Present: A Sensory Analysis of Carved Stone Balls, in: World Archaeology, 31, 2, 258-271.

Maggidis, C. 1994. Burial Building 19 at Archanes: A Study of Prepalatial and Early Protopalatial Funerary Architecture and Ritual, University of Pennsylvania (PhD Dissertation). 
Martinez, K. and Cupitt, J. 2005. VIPS - a Highly Tuned Image Processing Software Architecture, in: Conference Proceedings, IEEE International Conference on Image Processing 2, 574-577, Genova.

Masuda, T. and Yamada, Y. 2004. Sunlight Illumination Simulation for Archaeological Investigation - Case Study of the Fugoppe Cave, in: Conference Proceedings, 10th International Conference on Virtual Systems and MultiMedia.

Matusik, W., Pfister, H., Brand, M. and McMillan, L. 2002. A Data-Driven Reflectance Model. ACM Transactions on Graphics. 22(3)

Merrell, P. 2007. Example-Based Model Synthesis. New York, Assoc Computing Machinery.

Michelis, P. A. 1955. An Aesthetic Approach to Byzantine Art. London: B. T. Batsford Ltd.

Müller P, Wonka P, Haegler S, Ulmer A, Van Gool L, 2006: Procedural Modeling of Buildings, ACM Transactions on Graphics, 25:614-623.

Müller, G., Gerhard H. Bendels, and Reinhard Klein 2005. Rapid Synchronous Acquisition of Geometry and BTF for Cultural Heritage Artefacts. In proceedings of The 6th International Symposium on Virtual Reality, Archaeology and Cultural Heritage (VAST), Eurographics Association, pages 13-20, Eurographics Association, Nov. 2005 Presented at The 6th International Symposium on Virtual Reality, Archaeology and Cultural Heritage (VAST)

Müller, P, G. Zeng, P. Wonka and Van Gool, L. 2007. Image-based Procedural Modeling of Facades. In Proceedings of ACM SIGGRAPH 2007 / ACM Transactions on Graphics (TOG), ACM Press, Vol. 26, No. 3, article 85

Müller, P., Vereenooghe, T., Wonka, P., Paap, I., Van Gool, L. 2006. Procedural 3D Reconstruction of Puuc Buildings in Xkipché, in: M. Ioannides, D. Arnold, F. Niccolucci, K. Mania (eds), Conference Proceedings, 7th VAST International Symposium on Virtual Reality, Archaeology and Cultural Heritage 2006, Baltimore, Maryland, USA, Eurographics.

Pensabene, P., Lazzarini, L., Preite Martinez, A., Turi, B. 2007. Ostiensium marmorum decus et decor: studi architettonici, decorativi e archeometrici. L'Erma di Bretschneider, Rome.

Paliou, E, Wheatley, D and Earl, G. 2011. Three-dimensional visibility analysis of architectural spaces: iconography and visibility of the wall paintings of Xeste 3 (Late Bronze Age Akrotiri). Journal of Archaeological Science.

Paliou, E. and Wheatley, D. 2007. Integrating spatial analysis and 3D modelling approaches to the study of visual space: Late Bronze Age Akrotiri, in: Conference Proceedings, The XXXIII CAA 2005, Computer Applications and quantitative methods in Archaeology, International Conference, The world is in your eyes.

Paliou, E., Wheatley, D., Earl, G. P., 2011. Three-dimensional Visibility Analysis of Architectural Spaces: Iconography and Visibility of the Wall Paintings of Xeste 3 (Late Bronze Age Akrotiri), in: Journal of Archaeological Science, 38, 375-386.

Papadatos, Y. 1999. Mortuary Practices and their Importance for the Reconstruction of Society and Life in Prepalatial Crete: The evidence from Tholos Tomb $\Gamma$, in ArchanesPhourni. University of Sheffield (PhD Dissertation).

Papadopoulos, C and Earl, G. 2009. Structural and Lighting Models for the Minoan Cemetery at Phourni, Crete, in: K. Debattista, C. Perlingieri, D. Pitzalis, and S. Spina (eds), Conference Proceedings, 10th VAST International Symposium on Virtual Reality, Archaeology and Cultural Heritage 2009. 
Papadopoulos, C. and Sakellarakis, Y. (forthcoming), „Virtual Windows to the Past: Reconstructing the 'Ceramics Workshop' at Zominthos, Crete", in: F. Contreras and F. J. Melero, Conference Proceedings, The XXXVIII Conference on Computer Applications \& Quantitative Methods in Archaeology 2010.

Papadopoulos, C. 2010. Death management and virtual pursuits: A virtual reconstruction of the Minoan cemetery at Phourni, Archanes, examining the use of Tholos Tomb C and Burial Building 19 and the role of illumination, in relation to mortuary practices and the perception of life and death by the living. Archaeopress - British Archaeological Reports 2082.

Parisinou, E. 2007. Lighting Dark Rooms: Some Thoughts about the Use of Space in Early Greek Domestic Architecture, in: R. Westgate, N. Fisher, J. Whitley (eds), Conference Proceedings, Building Communities: House, Settlement and Society in the Aegean and Beyond, British School at Athens Studies 15.

Parker, M. P. 1999. The Archaeology of Death and Burial, Great Britain, Sutton Publishing Limited.

Paroli, L. 2005. The Basilica Portuense. In Portus. An Archaeological Survey of the Port of the Imperial Rome, eds. S. Keay, M. Millet, L. Paroli and K. Strutt. London: Archaeological Monographs of the British School at Rome.

Potamianos, J. 1996. Light into Architecture: Evocative Aspects of Natural Light as Related to Liturgy in Byzantine Churches. University of Michigan. USA. PhD Dissertation.

Potamianos, J. 2000. To Phos sti Byzantini Ekklisia (Light in Byzantine Church - in Greek). Thessaloniki: University Studio Press.

Richardson, A. 2003. Corridors of Power. Antiquity 77: 296 pp. 373-384

Roussos, I. 2003a. Image Based Flame Lighting, PhD Dissertation, University of Bristol.

Roussos, I. 2003b. High Fidelity Lighting of Knossos, in: D. Arnold, A. Chalmers, F. Niccolucci (eds), Conference Proceedings, 4th VAST International Symposium on Virtual Reality, Archaeology and Intelligent Cultural Heritage 2003, 47-56.

Sakellarakis, Y. and Panagiotopoulos, D. 2006. Minoan Zominthos, in: E. Gavrilaki, Y. Tzifopoulos (eds), Conference Proceedings, O Mylopotamos apo tin Archaiotita os Simera. Perivallon, Archaiologia, Istoria, Laografia, Koinoniologia, Rethymno.

Sakellarakis, Y. and Sapouna-Sakellaraki, E. 1976. Anaskafh Archanon, in: Praktika ths en Athinais Arxaiologikhs Etaireias, 351-385.

Sakellarakis, Y. and Sapouna-Sakellaraki, E. 1997. Archanes: Minoan Crete in a New Light, Vol. 1-2. Athens, Ammos Publications \& Eleni Nakou Foundation.

Scarre, C. and Lawson, G. (eds) 2006. Archaeoacoustics, McDonald Institute Monographs.

Shaw, J. and Shaw, M. 1996. Kommos I: The Kommos Region and Houses of the Minoan Town, Princeton University Press, USA.

Soles, J. 1992. The Prepalatial Cemeteries at Mochlos and Gournia and the House Tombs of Bronze Age Crete, in: Hesperia Supplements, 24, New Jersey, American School of Classical Studies at Athens.

Sundstedt, V. Chalmers, A. Martinez, P. 2004. High Fidelity Reconstruction of the Ancient Egyptian Temple of Kalabsha, in: Conference Proceedings, 3rd International Conference on Computer Graphics, Virtual Reality, Visualisation and Interaction in Africa 
Triantafyllides, G. 1964. Stoicheia Physikou Photismou ton Vyzatninon Ekklisiwn (Elements of Physical Lighting in Byzantine Churches - in Greek). Athens: Ypiresia Archaiotiton kai Anastiloseos. Dimosieumata tou Archaiologikou Deltiou. 3.

Trigger, G. B. 2006. A History of Archaeological Thought, USA, Cambridge University Press.

Unver, R. and Enarum, D. 1999. A Comparative Investigation of Lighting of Mosques and Churches in Istanbul, in Proceedings of the 24th Session of the CIE in Warsaw.

Whittemore, T. 1933. The Mosaics of Hagia Sophia at Istanbul: Preliminary Report on the First Year's Work 1931-32. V. 1. London: Oxford University Press for the Byzantine Institute.

Weidlich, A. and Wilkie, A. 2008. Modeling aventurescent gems with procedural textures. In proceedings of the spring conference on computer graphics (SCCG). pp1-8 ACM

Wilkie, A., Weidlich, A., Magnor, M. And Chalmers, A. 2009. SIGGRAPH Asia 2009 Course Notes: Predictive Rendering. ACM.

Wonka, P., M. Wimmer, et al. 2003. Instant architecture. ACM Transactions on Graphics 22(3): 669-677.

Woodson, W. 1992. Human Factors Design Handbook: Information and Guidelines for the Design of Systems, Facilities, Equipment, and Products for Human Use, 2nd edition, New York, McGraw-Hill.

Yang, P.P.J, Putra, S.Y., and Li, W. 2007. Viewsphere: a GIS-based 3D visibility analysis for urban design evaluation, in Planning and design: Environment and Planning B, 34(6):971992

Zacharias J 2001. Pedestrian behavior and perception in urban walking environments. Journal of Planning Literature, 16,1, 3-18.

Zányi, E. 2007. High Dynamic Range Display of Authentically Illuminated Byzantine Art from Cyprus, in: D. Arnold, F. Niccolucci, A. Chalmers (eds), Conference Proceedings, 8th VAST International Symposium on Virtual Reality, Archaeology and Cultural Heritage 2007.

\section{Tables and Figures}

\begin{tabular}{|c|c|c|c|c|c|c|c|c|c|c|c|}
\hline ObserverID & Vertex & ObsX & ObsY & ObsZ & VerX & VerY & VerZ & Colour & XYAngle & XZAngle & Distance \\
\hline 1 & 1 & 22.3832 & 9.81843 & 2 & 27.7309 & 38.7952 & 5.97076 & 24.8358 & 79.5435 & 7.67477 & 29.7325 \\
\hline 100 & 1 & 18.3832 & 16.5684 & 2 & 27.7309 & 38.7952 & 5.97076 & 44.5642 & 67.1902 & 9.35136 & 24.4372 \\
\hline 1000 & 1 & 15.3832 & 39.0684 & 1.5 & 27.7309 & 38.7952 & 5.97076 & 83.3449 & 1.26758 & 19.8993 & 13.1351 \\
\hline 1001 & 1 & 16.3832 & 39.0684 & 1.5 & 27.7309 & 38.7952 & 5.97076 & 82.8049 & 1.37924 & 21.4977 & 12.1998 \\
\hline 1002 & 1 & 17.3832 & 39.0684 & 1.5 & 27.7309 & 38.7952 & 5.97076 & 82.1208 & 1.51247 & 23.3595 & 11.2756 \\
\hline 1003 & 1 & 18.3832 & 39.0684 & 1.5 & 27.7309 & 38.7952 & 5.97076 & 81.2392 & 1.67419 & 25.5509 & 10.3655 \\
\hline 1004 & 1 & 19.3832 & 39.0684 & 1.5 & 27.7309 & 38.7952 & 5.97076 & 80.0805 & 1.87461 & 28.1591 & 9.47352 \\
\hline 1005 & 1 & 20.3832 & 39.0684 & 1.5 & 27.7309 & 38.7952 & 5.97076 & 78.5239 & 2.12951 & 31.3009 & 8.60535 \\
\hline 1006 & 1 & 21.3832 & 39.0684 & 1.5 & 27.7309 & 38.7952 & 5.97076 & 76.3822 & 2.4646 & 35.1323 & 7.76894 \\
\hline 1007 & 1 & 22.3832 & 39.0684 & 1.5 & 27.7309 & 38.7952 & 5.97076 & 73.3584 & 2.92473 & 39.8591 & 6.97574 \\
\hline 1008 & 1 & 23.3832 & 39.0684 & 1.5 & 27.7309 & 38.7952 & 5.97076 & 68.9765 & 3.59582 & 45.7426 & 6.24223 \\
\hline 1009 & 1 & 24.3832 & 39.0684 & 1.5 & 27.7309 & 38.7952 & 5.97076 & 62.477 & 4.66572 & 53.0823 & 5.59195 \\
\hline 101 & 1 & 19.3832 & 16.5684 & 2 & 27.7309 & 38.7952 & 5.97076 & 41.4411 & 69.4152 & 9.49436 & 24.0724 \\
\hline
\end{tabular}




\begin{tabular}{|c|c|c|c|c|c|c|c|c|c|c|c|}
\hline 1010 & 1 & 25.3832 & 39.0684 & 1.5 & 27.7309 & 38.7952 & 5.97076 & 52.6842 & 6.63791 & 62.1354 & 5.05711 \\
\hline 1011 & 1 & 26.3832 & 39.0684 & 1.5 & 27.7309 & 38.7952 & 5.97076 & 37.8508 & 11.4597 & 72.9024 & 4.67748 \\
\hline 1012 & 1 & 27.3832 & 39.0684 & 1.5 & 27.7309 & 38.7952 & 5.97076 & 14.6492 & 38.1546 & 84.3506 & 4.49258 \\
\hline 1018 & 1 & 14.3832 & 40.1934 & 1.5 & 27.7309 & 38.7952 & 5.97076 & 83.6207 & 5.9801 & 18.424 & 14.1459 \\
\hline 1019 & 1 & 15.3832 & 40.1934 & 1.5 & 27.7309 & 38.7952 & 5.97076 & 83.1594 & 6.46046 & 19.7873 & 13.2064 \\
\hline 102 & 1 & 20.3832 & 16.5684 & 2 & 27.7309 & 38.7952 & 5.97076 & 38.045 & 71.7071 & 9.62686 & 23.7442 \\
\hline 1020 & 1 & 16.3832 & 40.1934 & 1.5 & 27.7309 & 38.7952 & 5.97076 & 82.5846 & 7.02432 & 21.3565 & 12.2766 \\
\hline 1021 & 1 & 17.3832 & 40.1934 & 1.5 & 27.7309 & 38.7952 & 5.97076 & 81.8577 & 7.69536 & 23.1787 & 11.3587 \\
\hline
\end{tabular}

Table 1: Sample numeric output from Texture Viewshed procedure for a single mesh

\begin{tabular}{|c|c|}
\hline Model Variant & $\begin{array}{c}\text { Illuminance Value } \\
(\mathbf{L u x})\end{array}$ \\
\hline 1 & 113 \\
\hline 2 & 65.4 \\
\hline 3 & 62.4 \\
\hline 4 & 212 \\
\hline 5 & 152 \\
\hline 6 & 40.8 \\
\hline 7 & 105 \\
\hline 8 & 99.1 \\
\hline 9 & 87.3 \\
\hline 10 & 43.0 \\
\hline
\end{tabular}

Table 2: Procedural variations of Clerestory windows produced in CityEngine and the illuminance values obtained by a light meter in 3dsMaxDesign. 


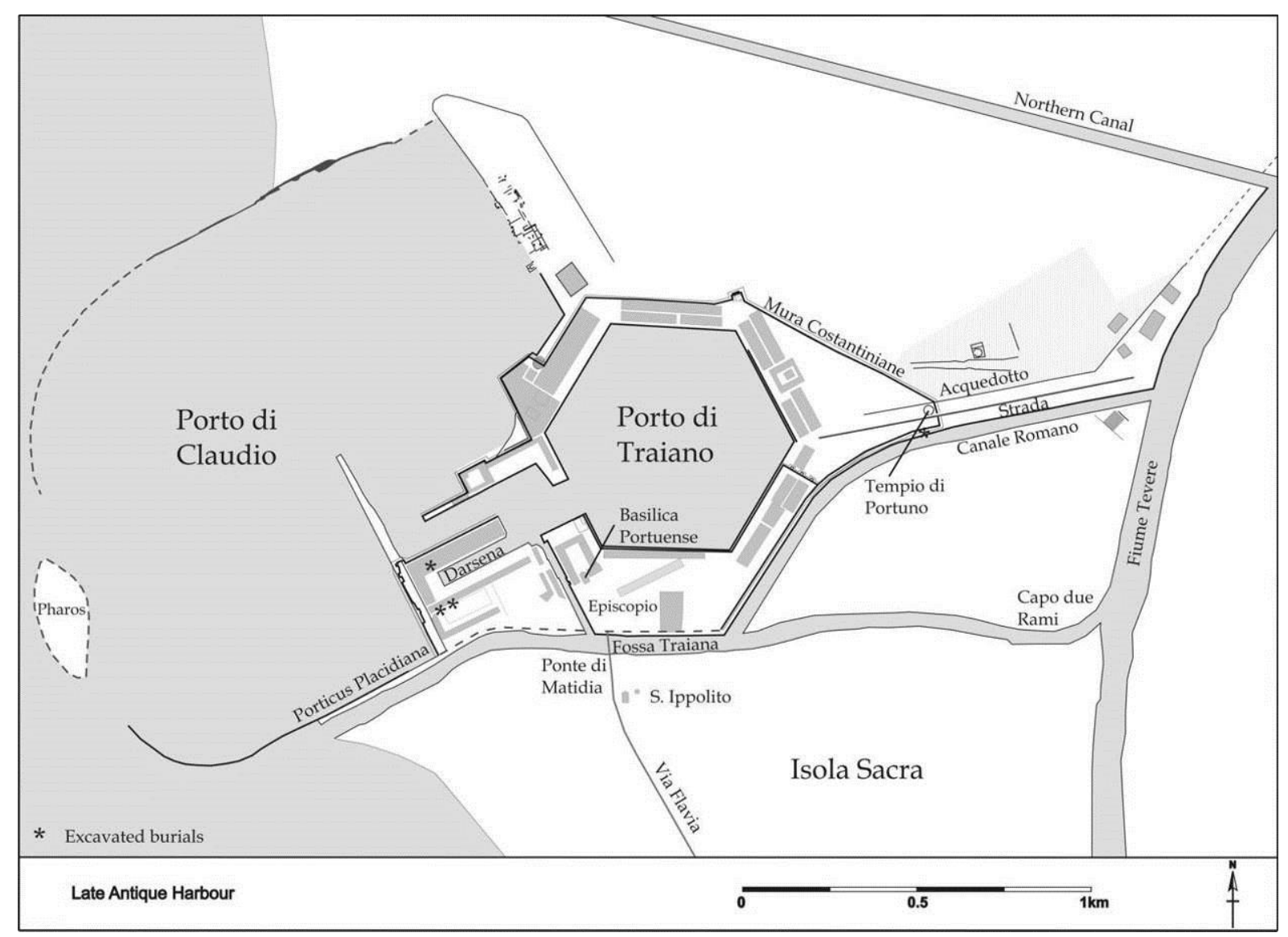

Figure 1. Map showing Portus and the Basilica Portuense (after Keay et al 2005)

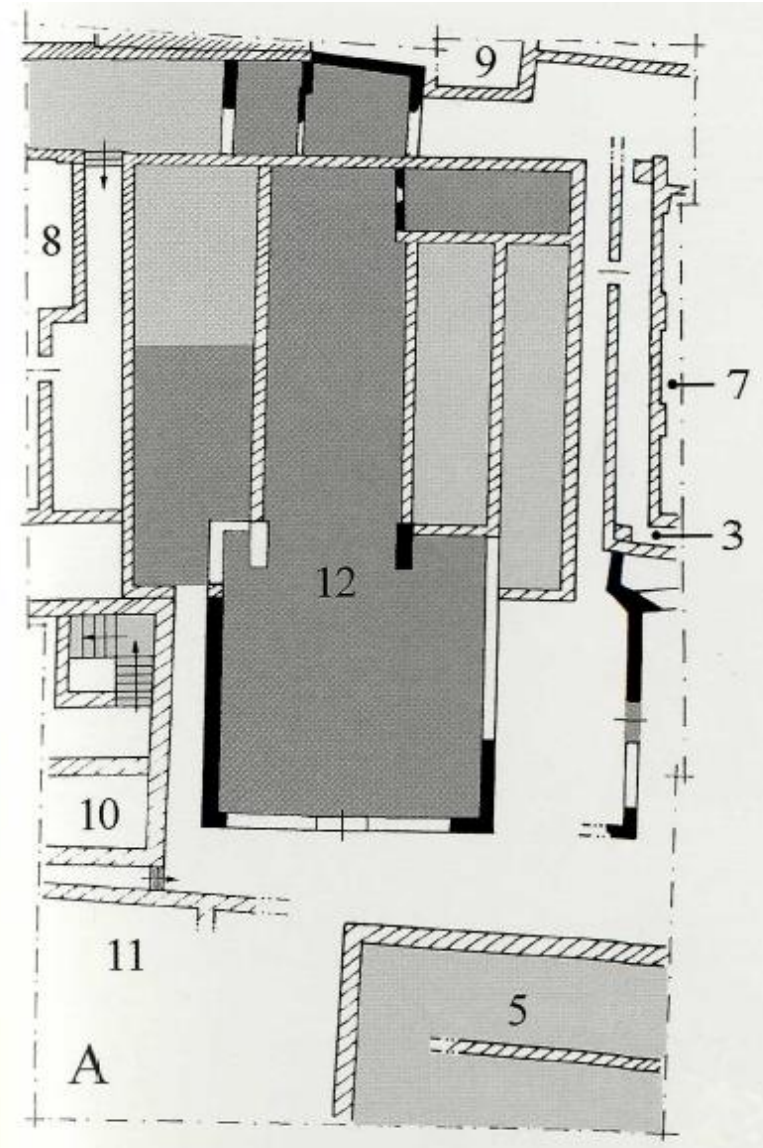


Figure 2. Plan of building phases I-II (after Paroli 2005)

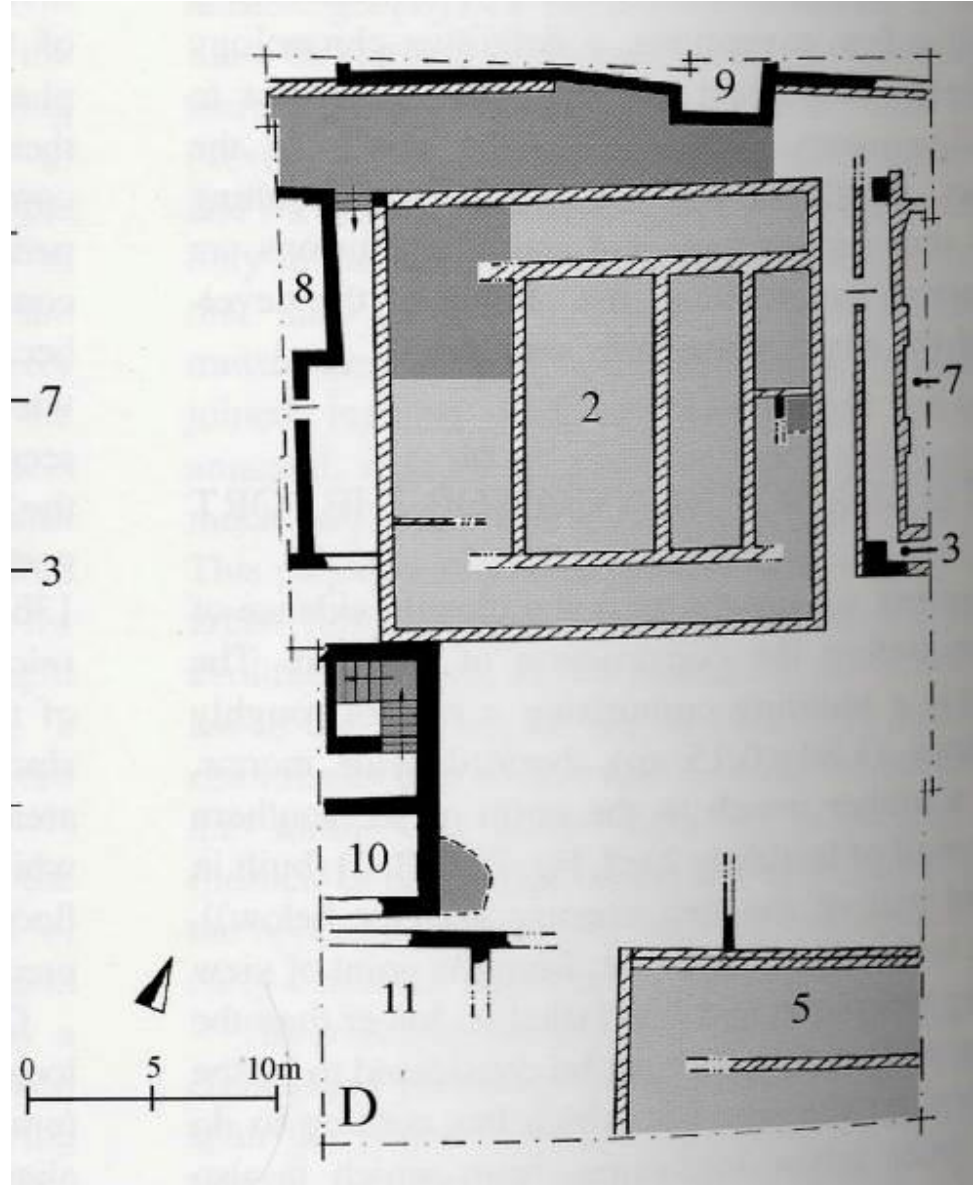

Figure 3. Plan of building phase III (after Paroli 2005) 


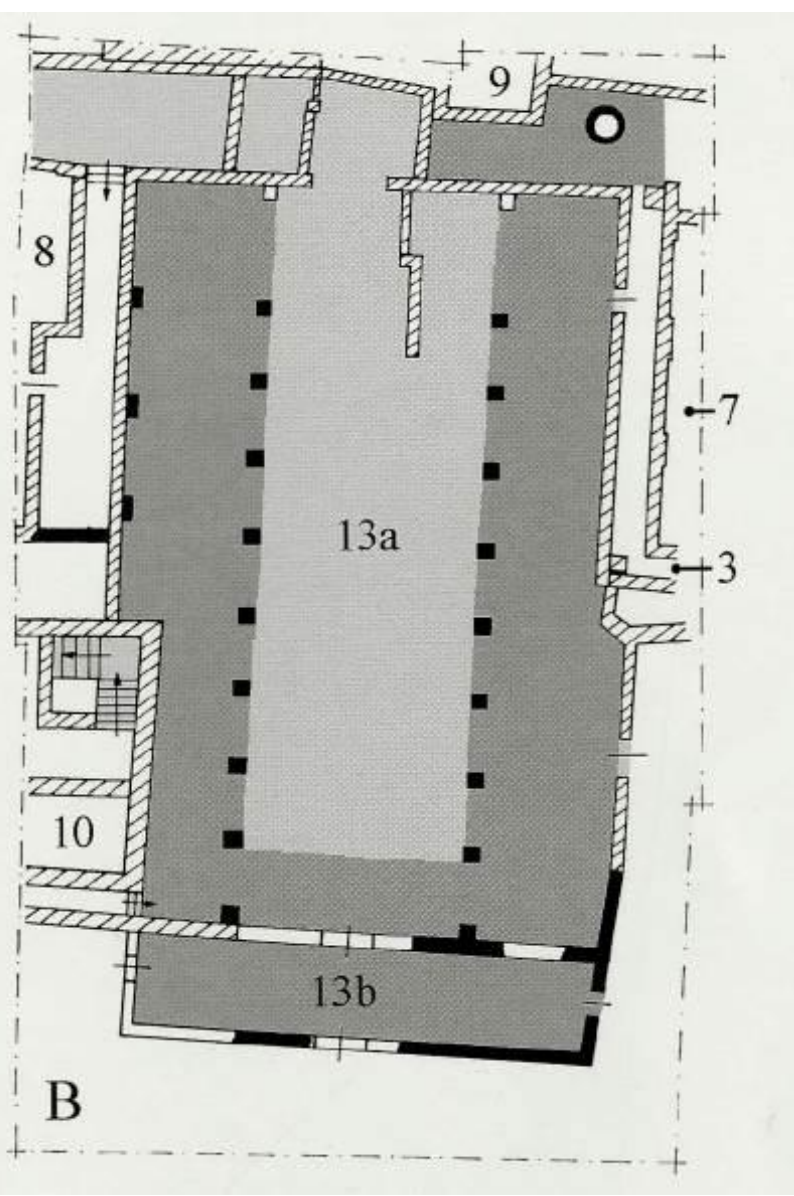

Figure 4. Phase 1 (after Paroli 2005) 


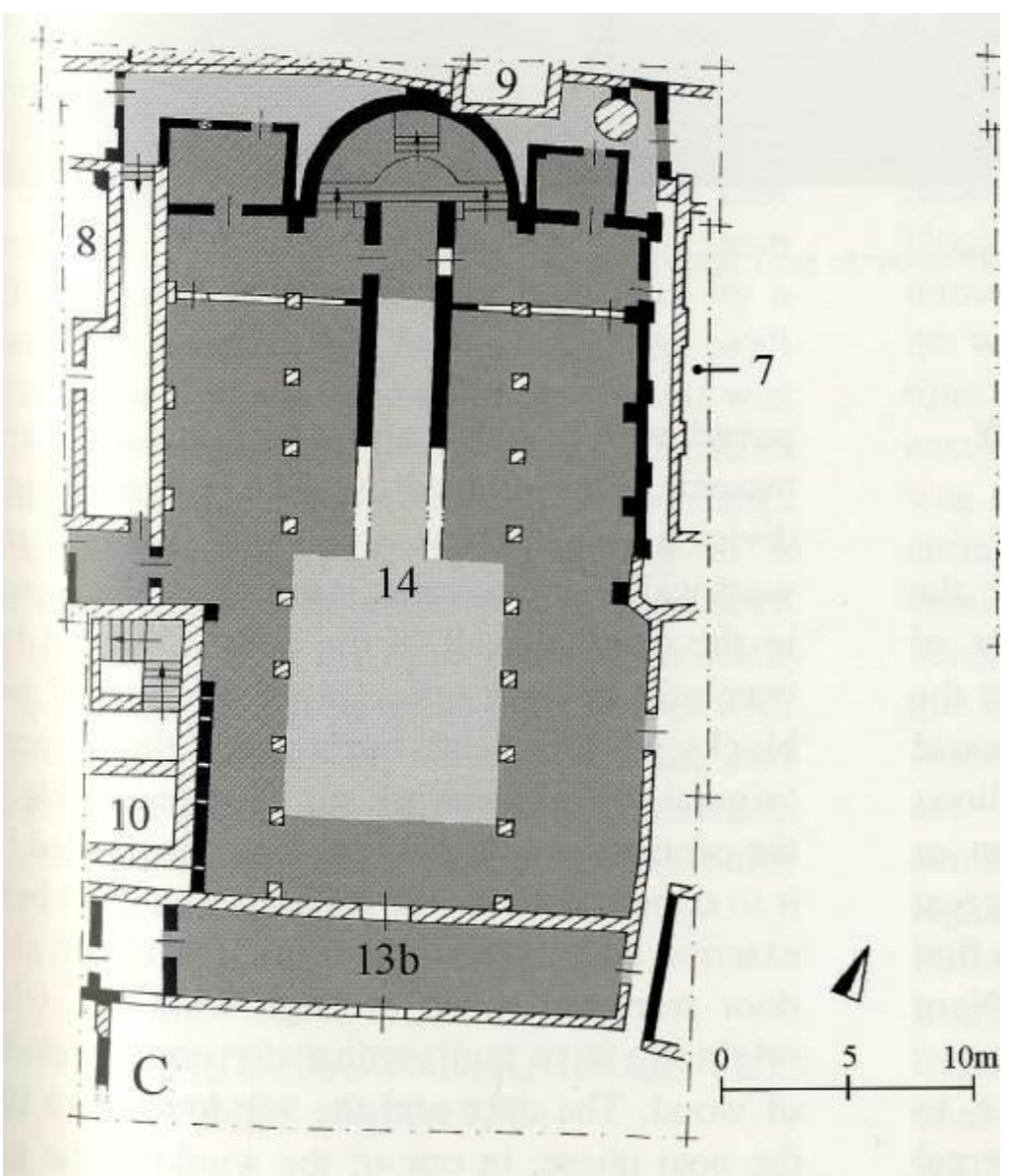

Figure 5. Phase 2 (after Paroli 2005) 


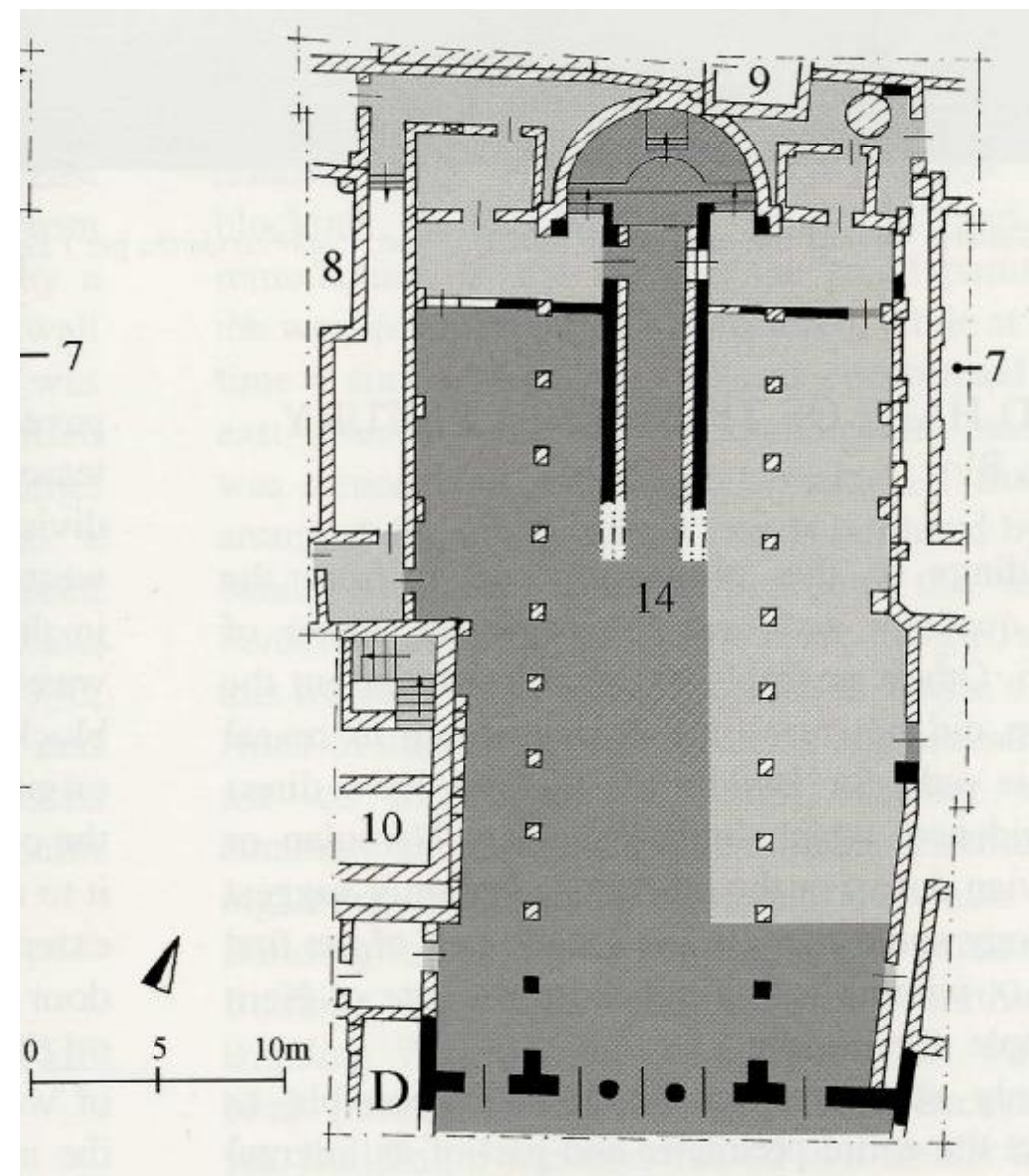

Figure 6. Phase 3 (after Paroli 2005) 


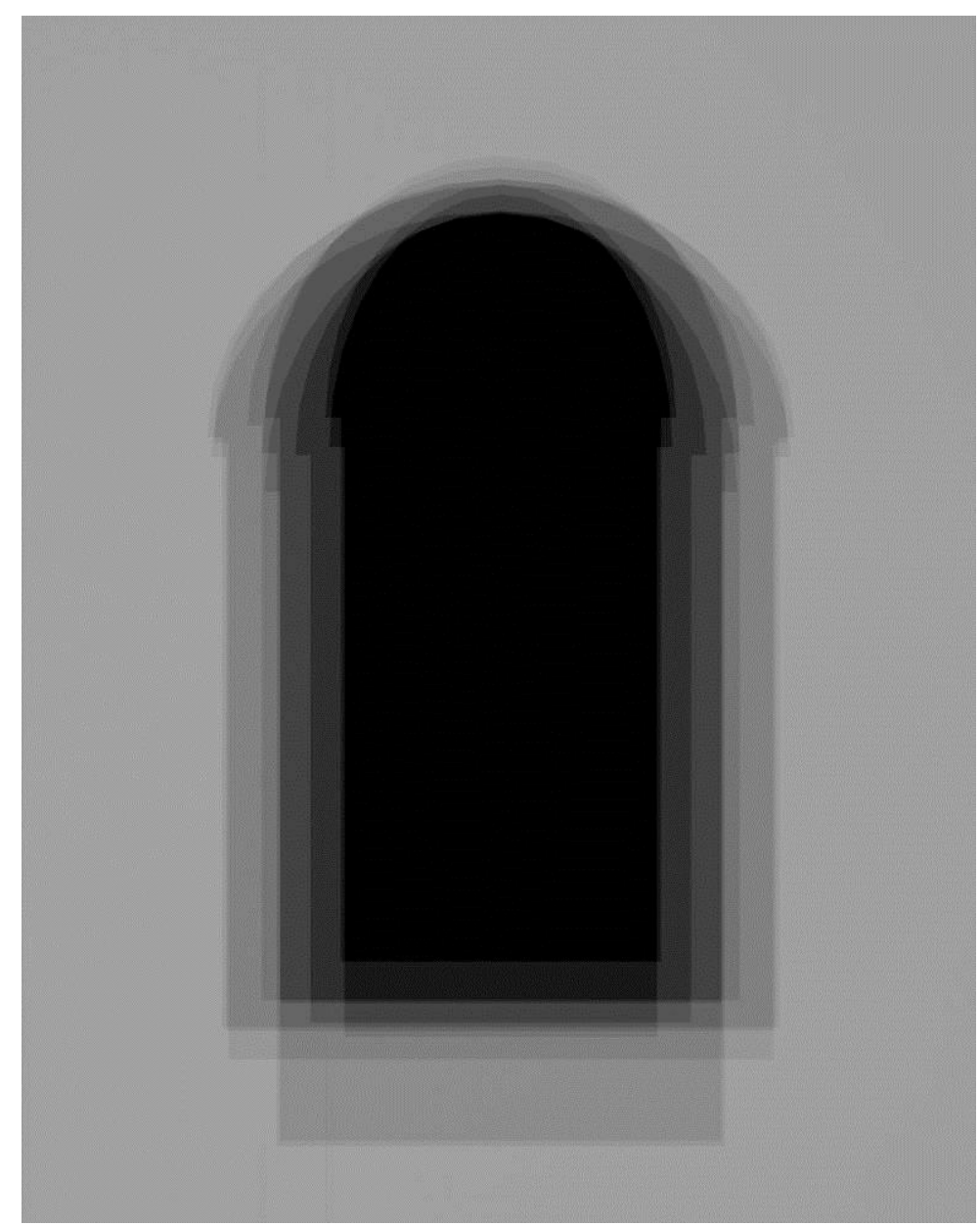

Figure 7. Visualisation of the clerestorey geometry generated procedurally in CityEngine (10 overlapping permutations each with $10 \%$ opacity) 

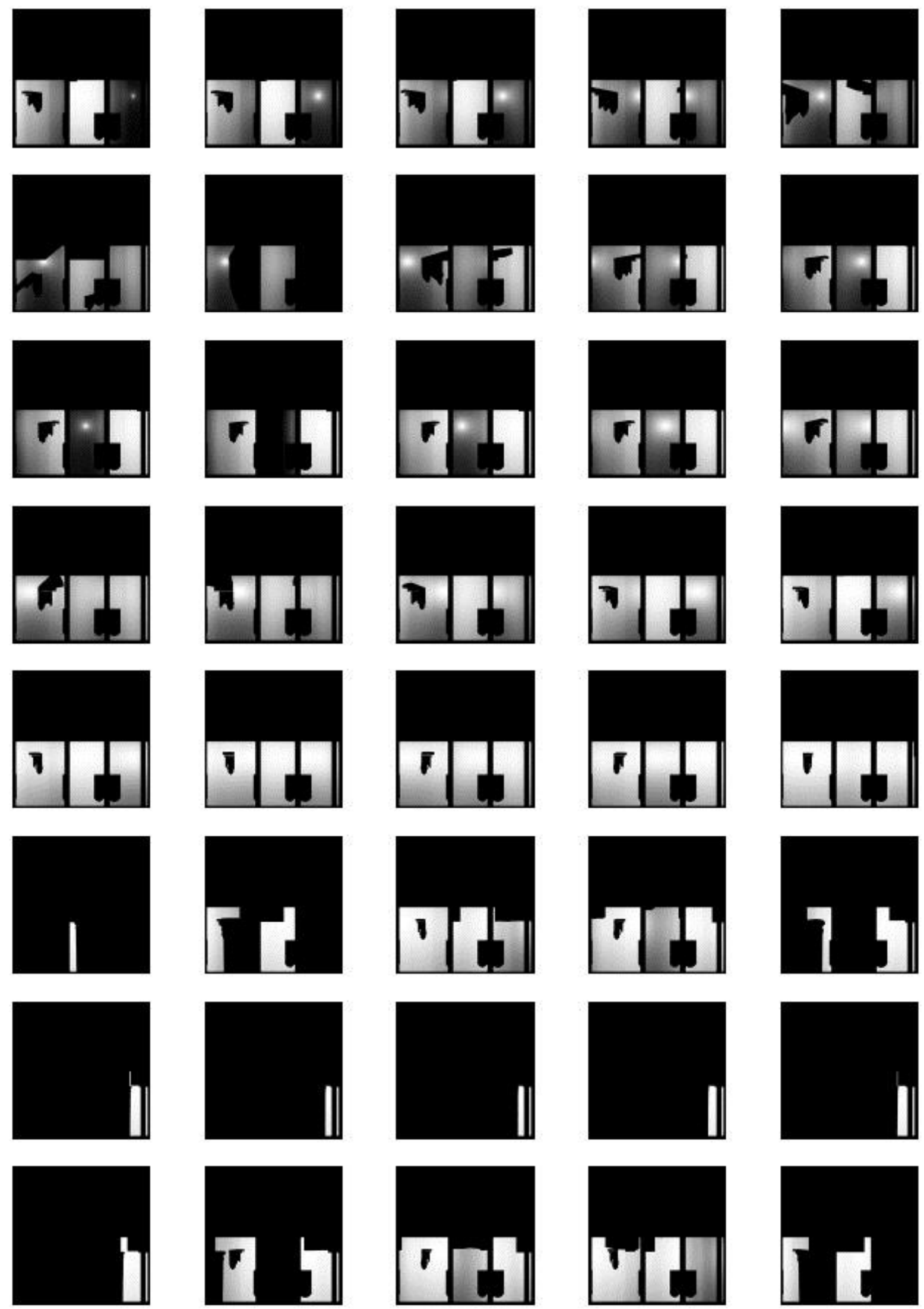

Figure 8. Sample of Texture Viewsheds produced 


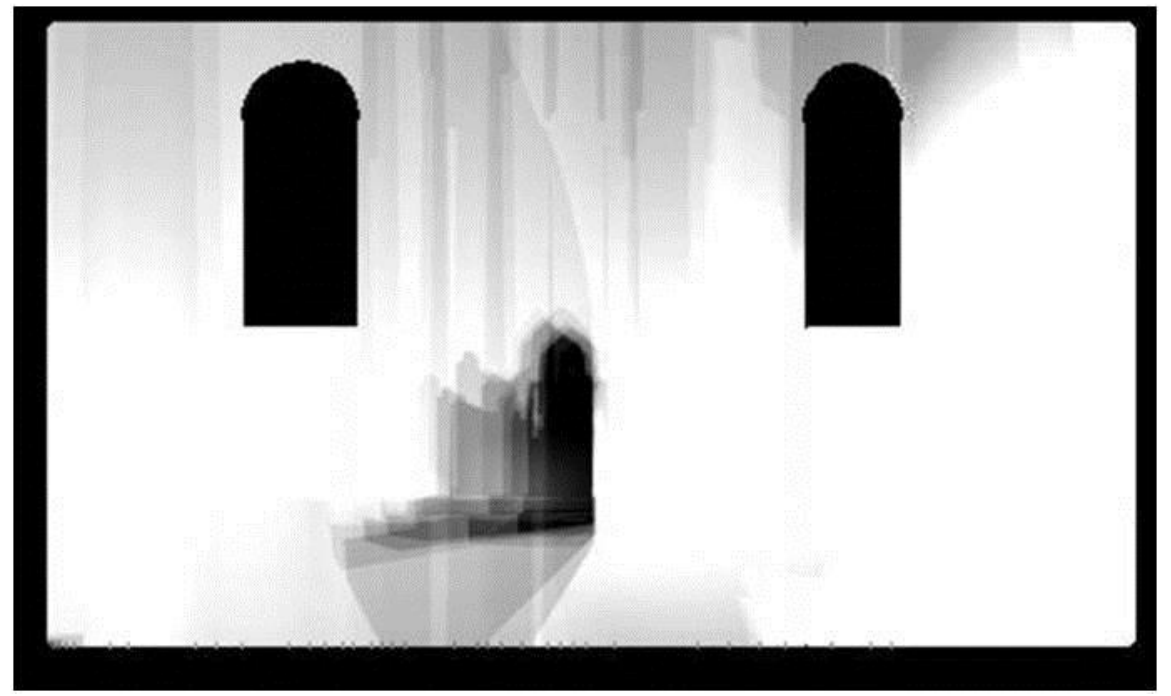

Figure 9. Example of a cumulative texture viewshed summary

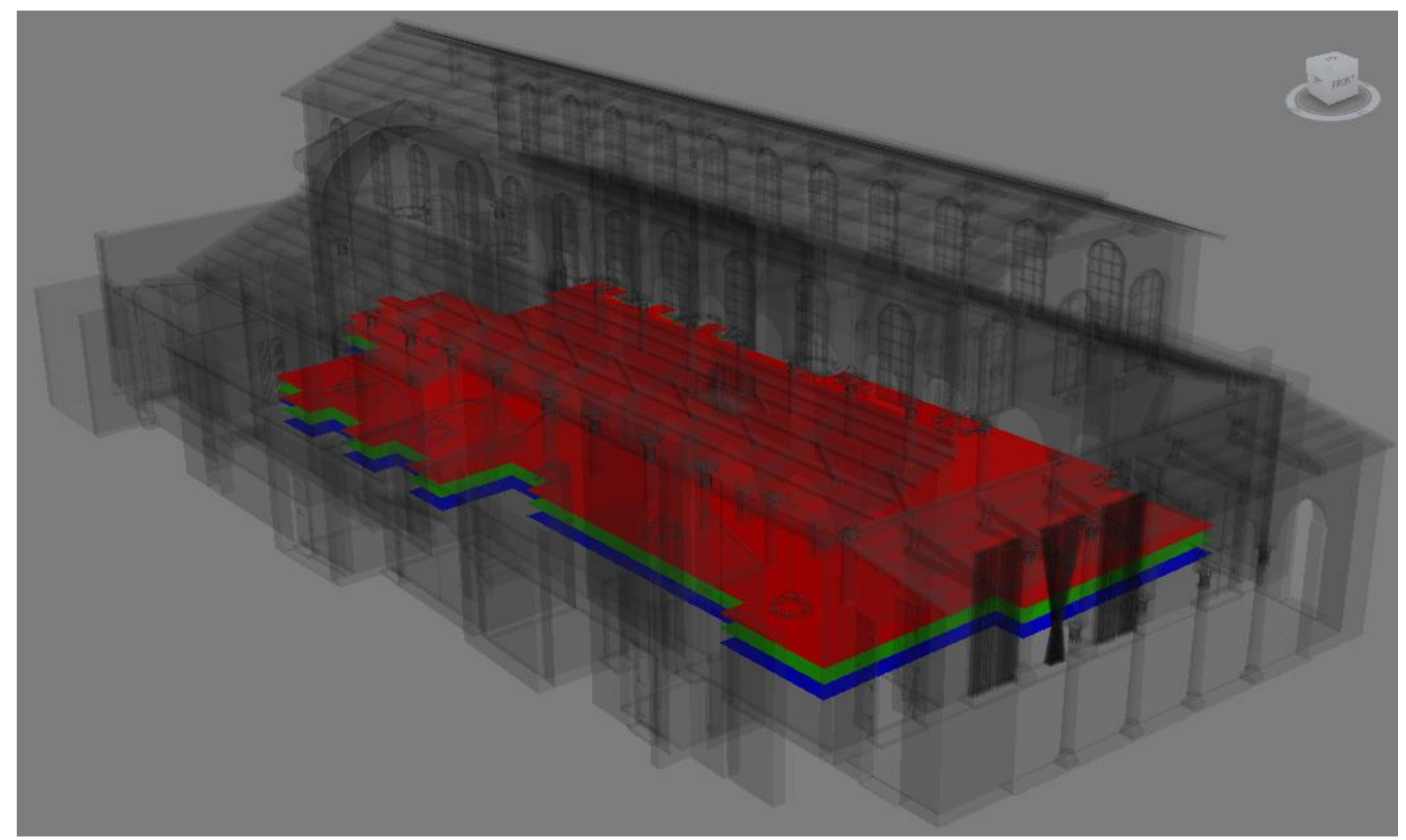

Figure 10. Planar geometry defining observers (Red 2m; Green 1.5m; Blue 1m) 


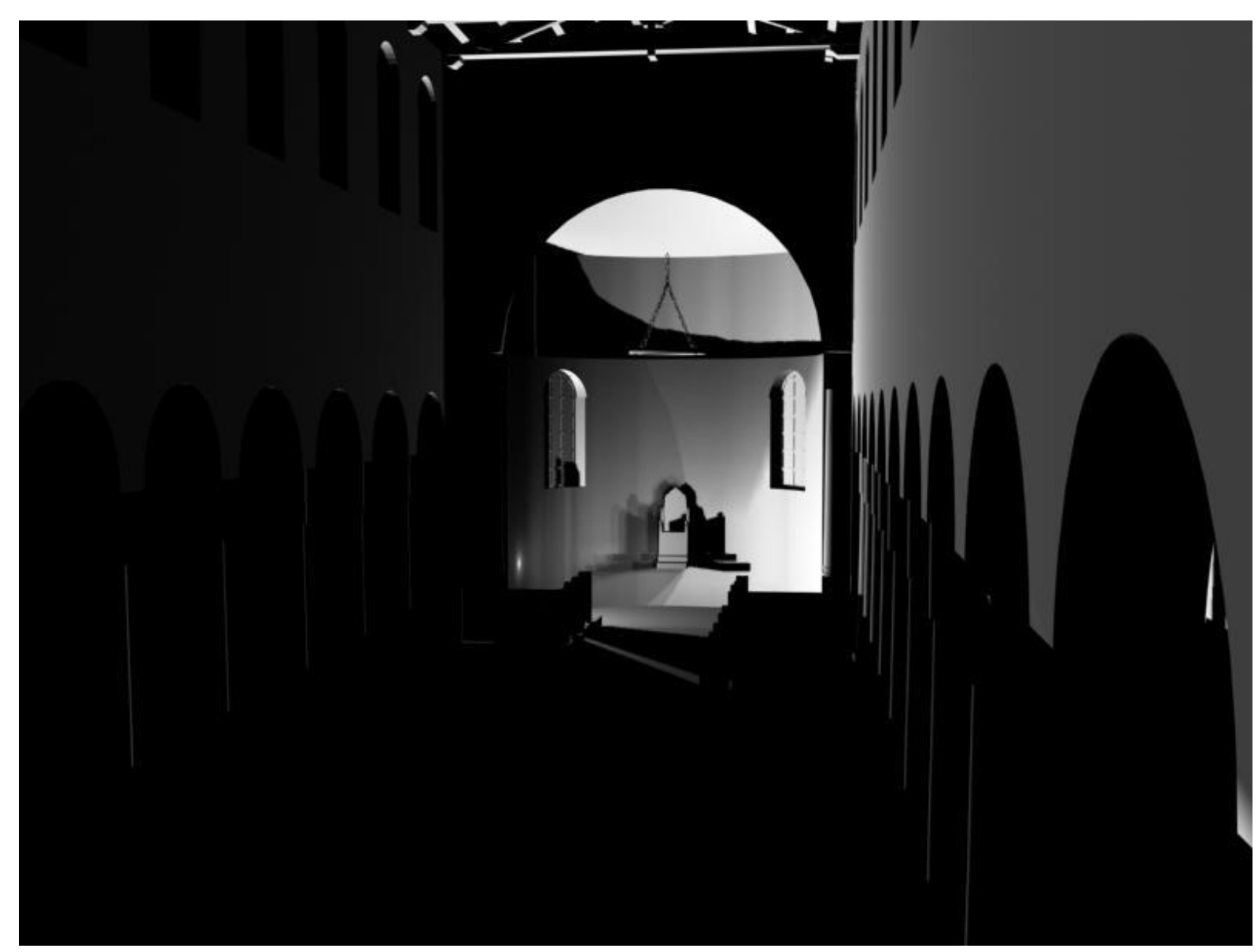

Figure 11. Geometry remapped with Texture Viewshed visibility data

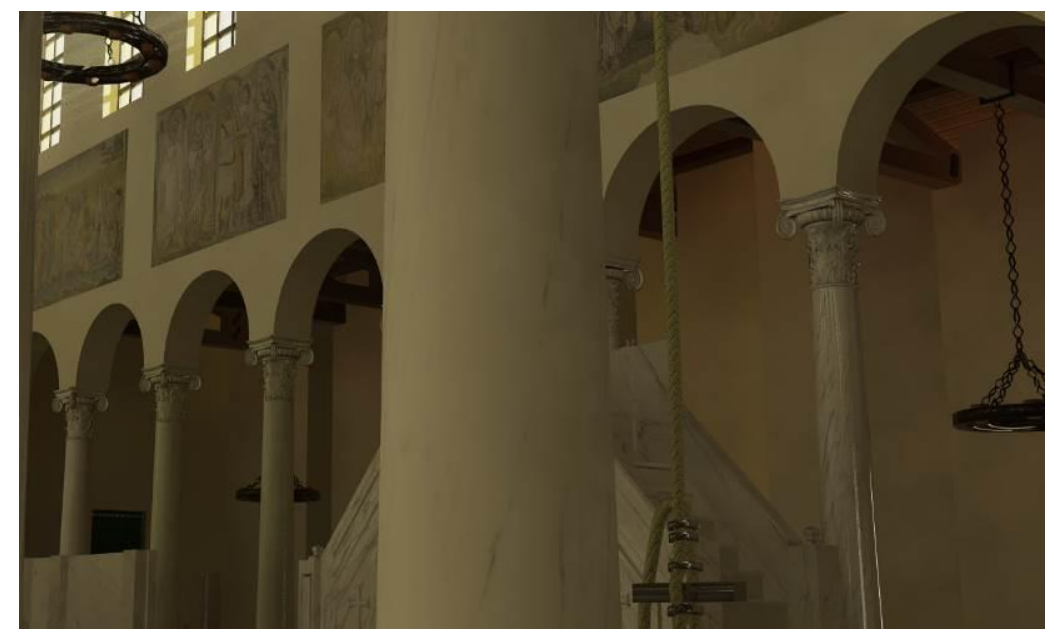

Figure 12. Render showing Basilica without additional windows to the east 


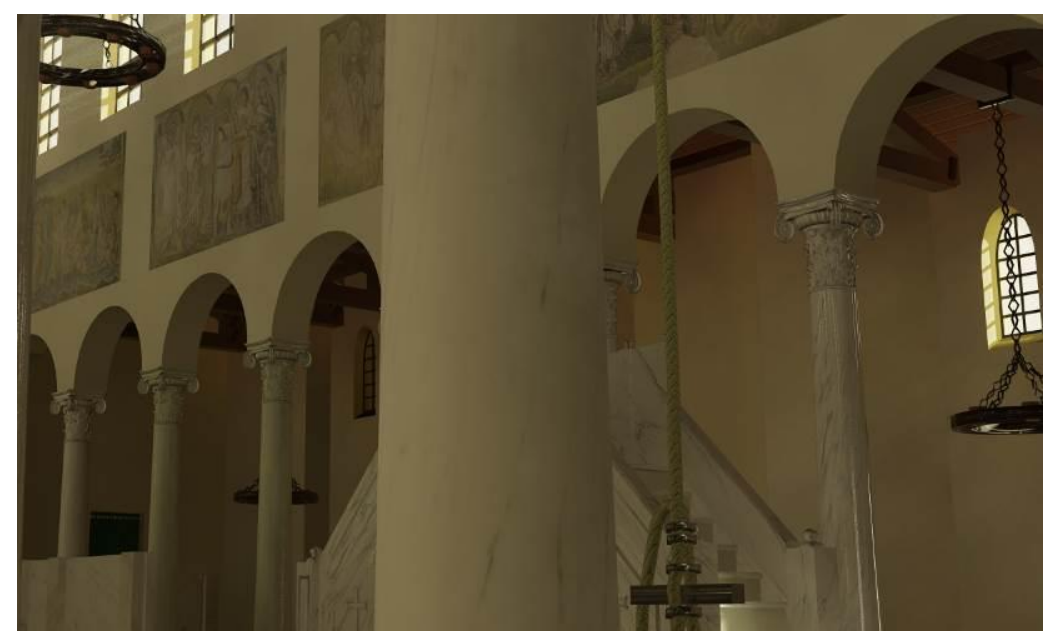

Figure 13. Render showing Basilica with additional windows to the east

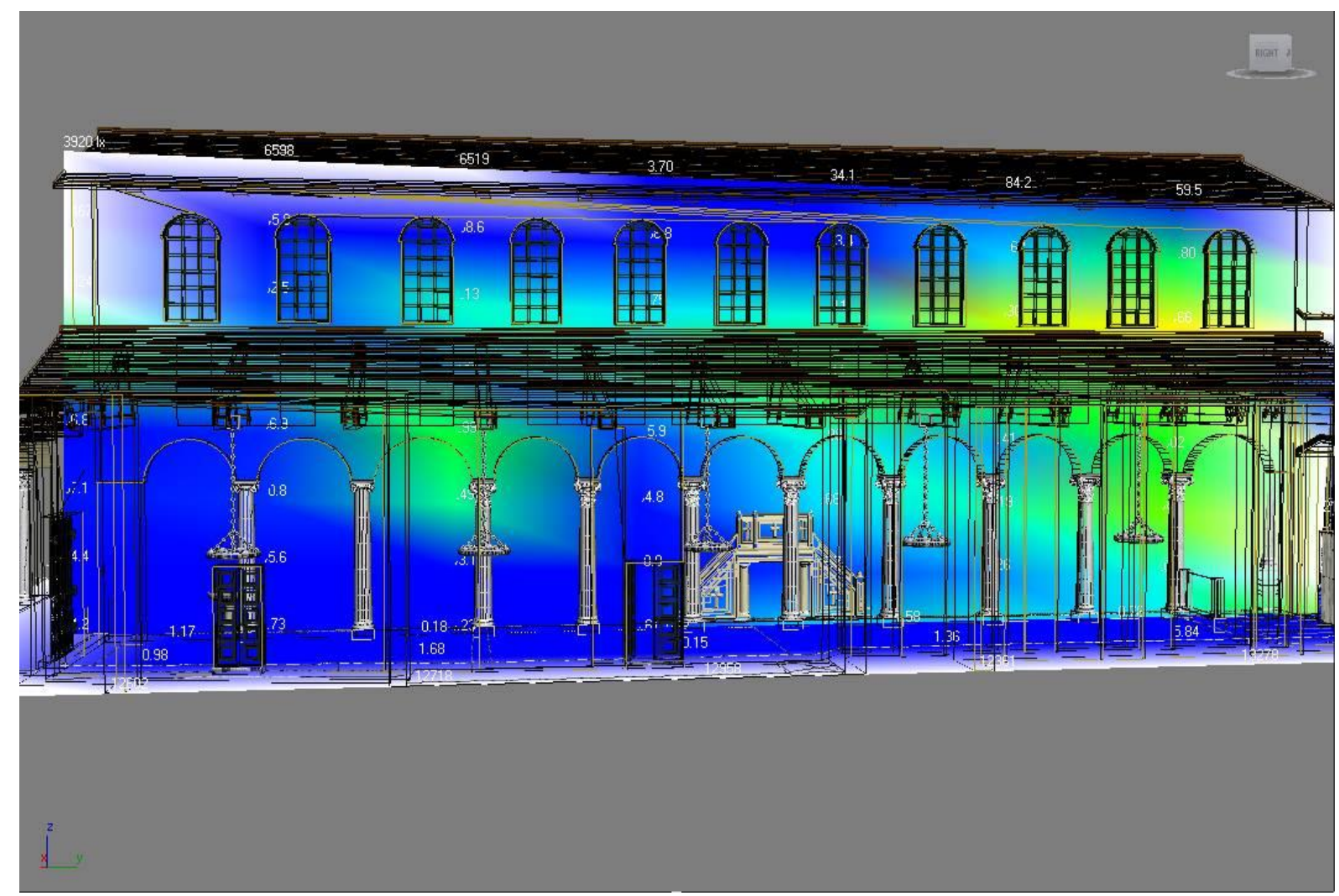

Figure 14. Light Meter indicating that the amount of light entering from the clerestory windows and the other openings linearly decreases as it reaches the floor of the Basilica. 


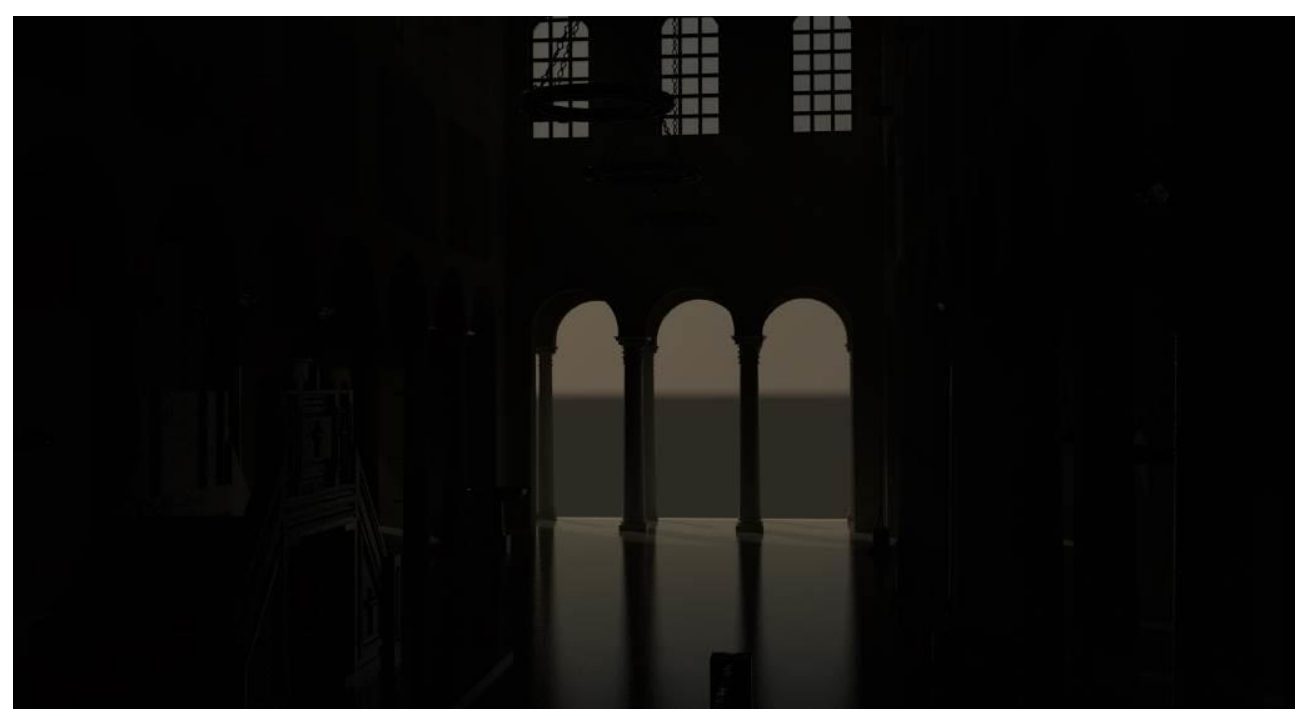

Figure 15. Render demonstrating low light levels, and the likely impact of luminance accommodation as an observer inside looks from the interior to the exterior.

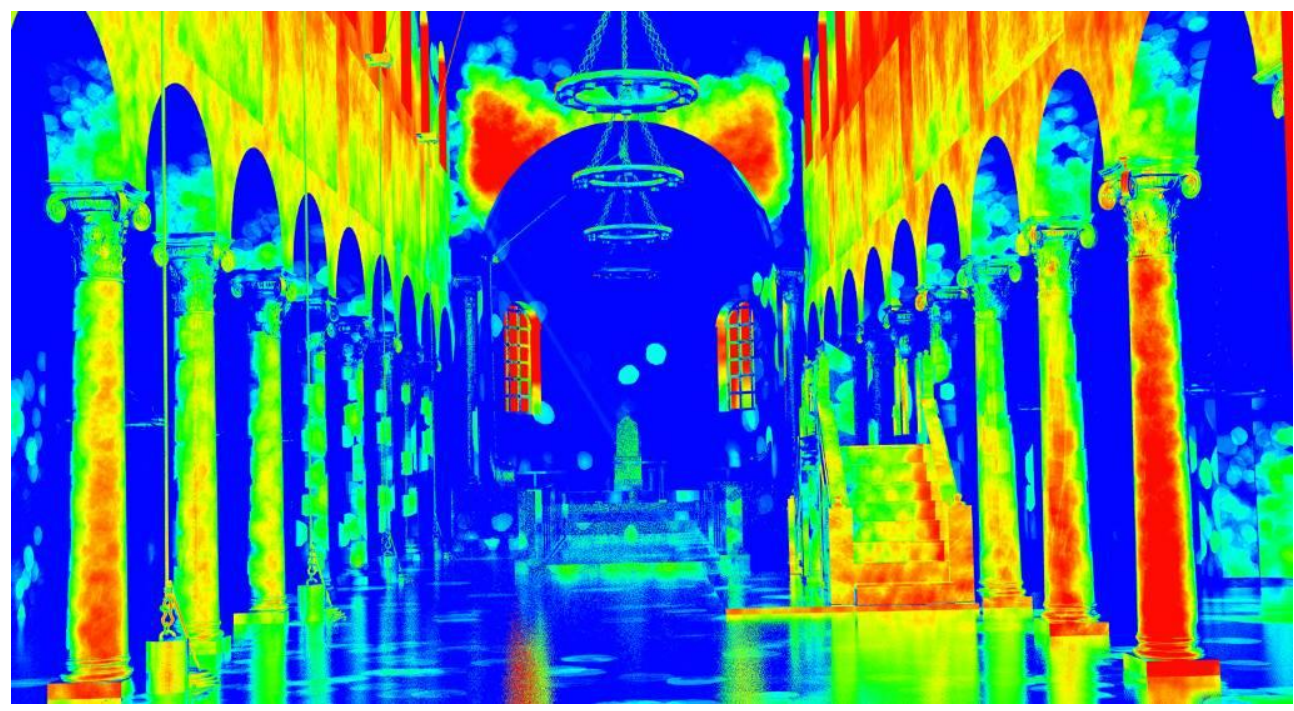

Figure 16. Pseudo-colour exposure of the nave of the Basilica at $1 \mathrm{pm}$. The lighting values show high levels of illumination at the upper walls of the nave gradually decreasing to the floor. The Ambon is well lit during the day, while the sanctuary is the area of the nave that is less lit. 


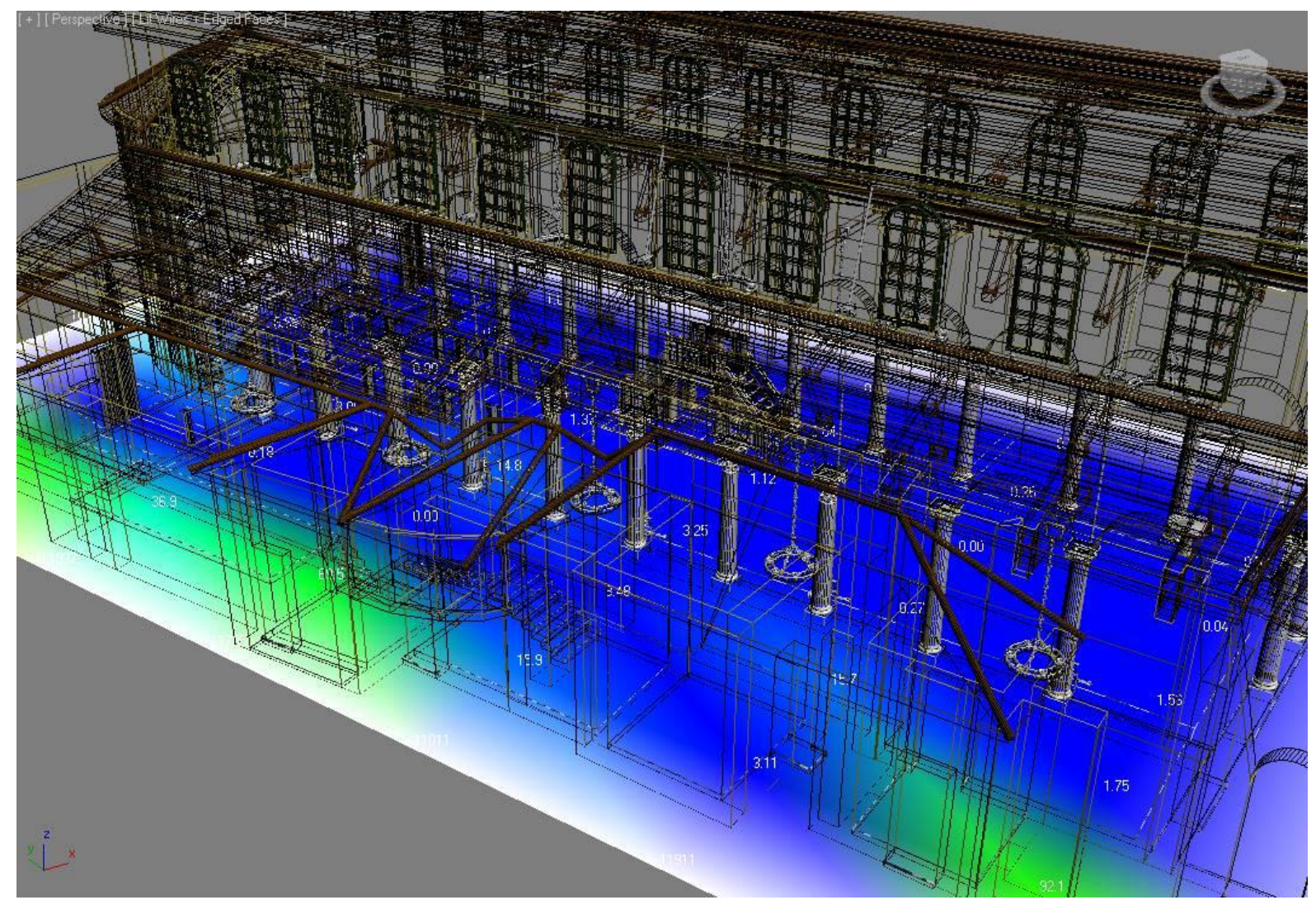

Figure 17. Light meter indicating the amount of light entering through the side openings mainly affecting the aisles

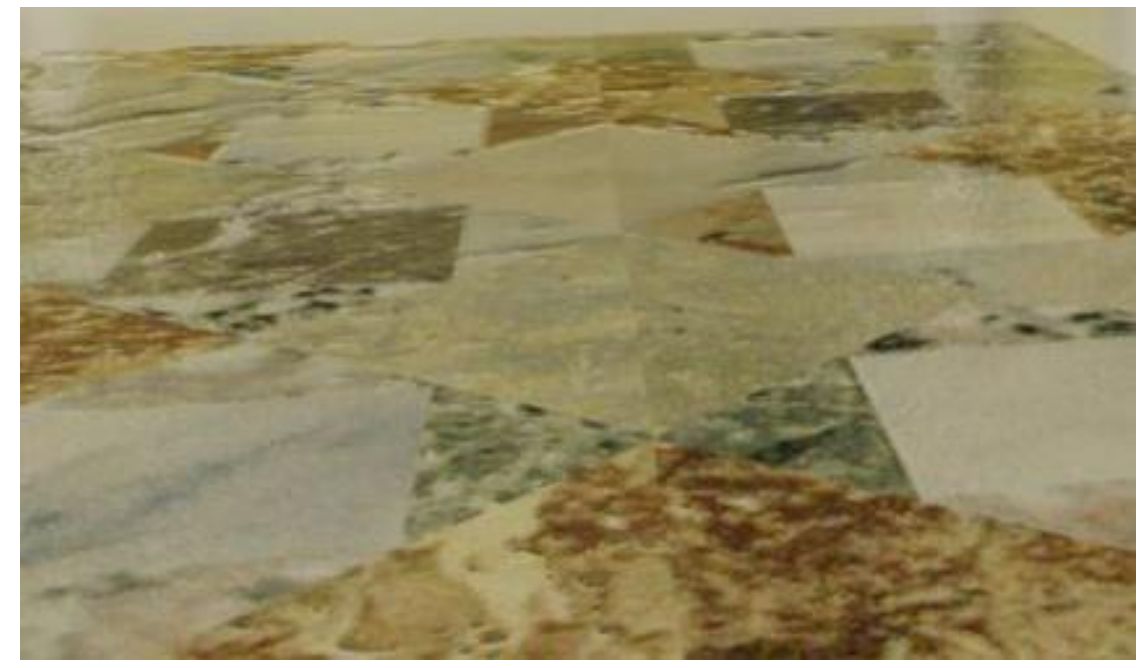

Figure 18. Rendering of Opus Sectile floor. 


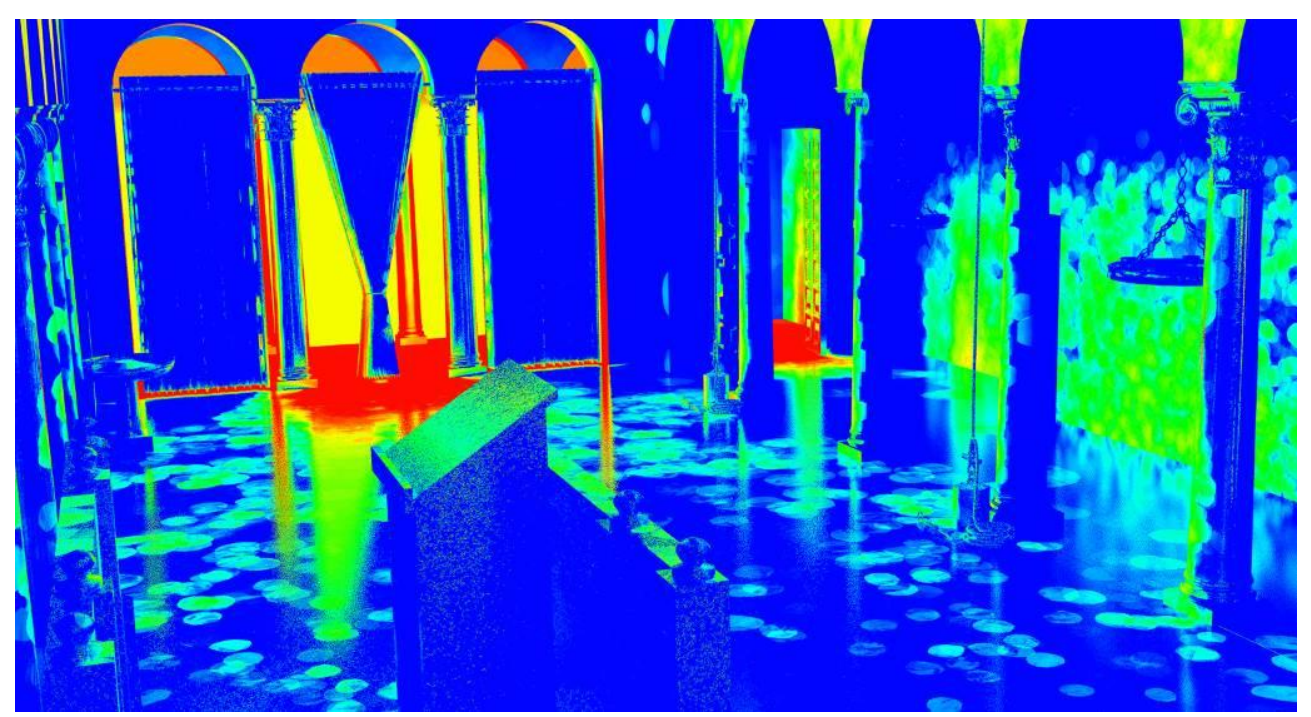

Figure 19. Pseudo-colour exposure indicating the reflections cause by the shiny surfaces

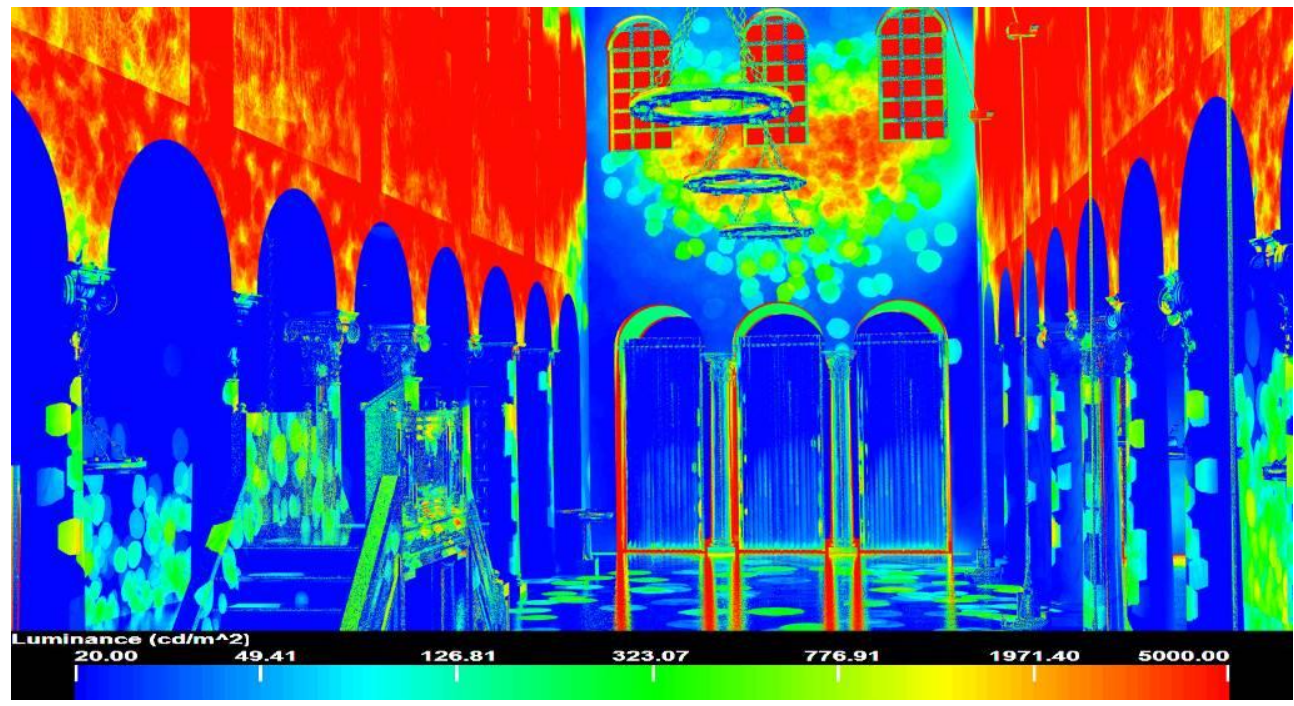

Figure 20. Pseudo-colour exposure of an alternative structural model with the curtains of the triforium closed 


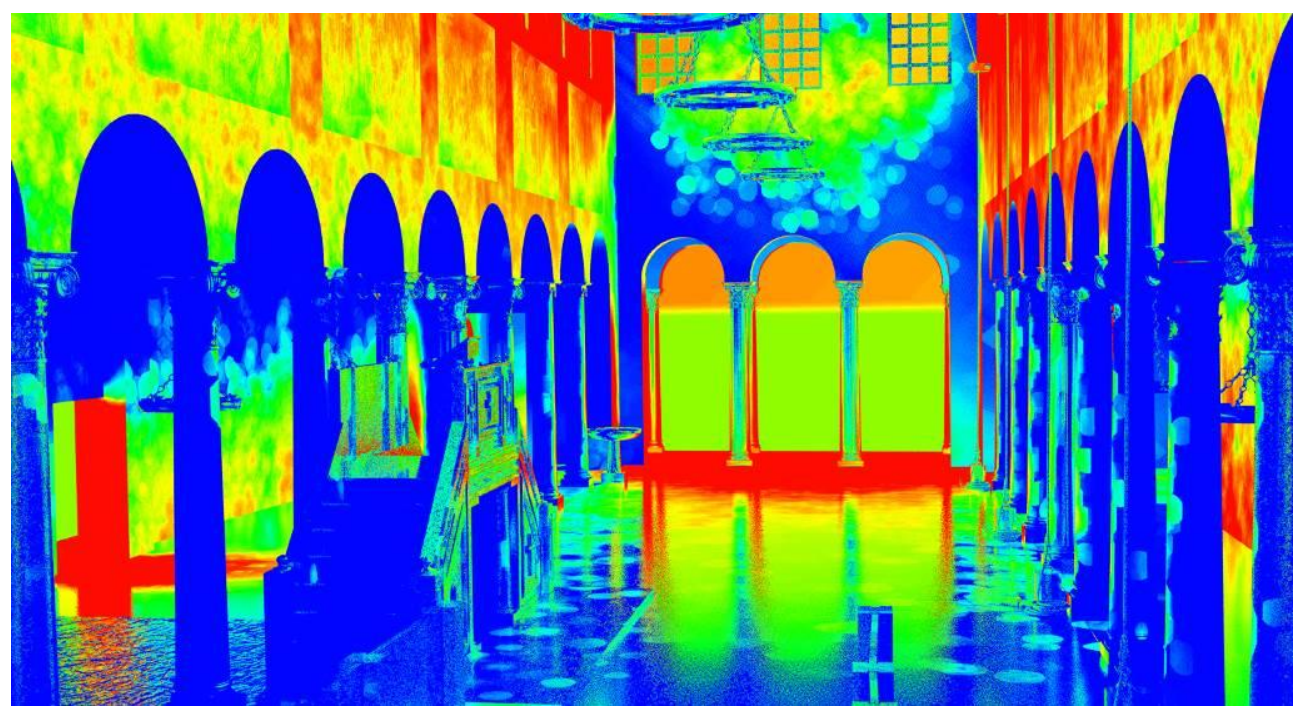

Figure 21. Pseudo-colour exposure of an alternative structural model with the curtains of the triforium and the side-doors open

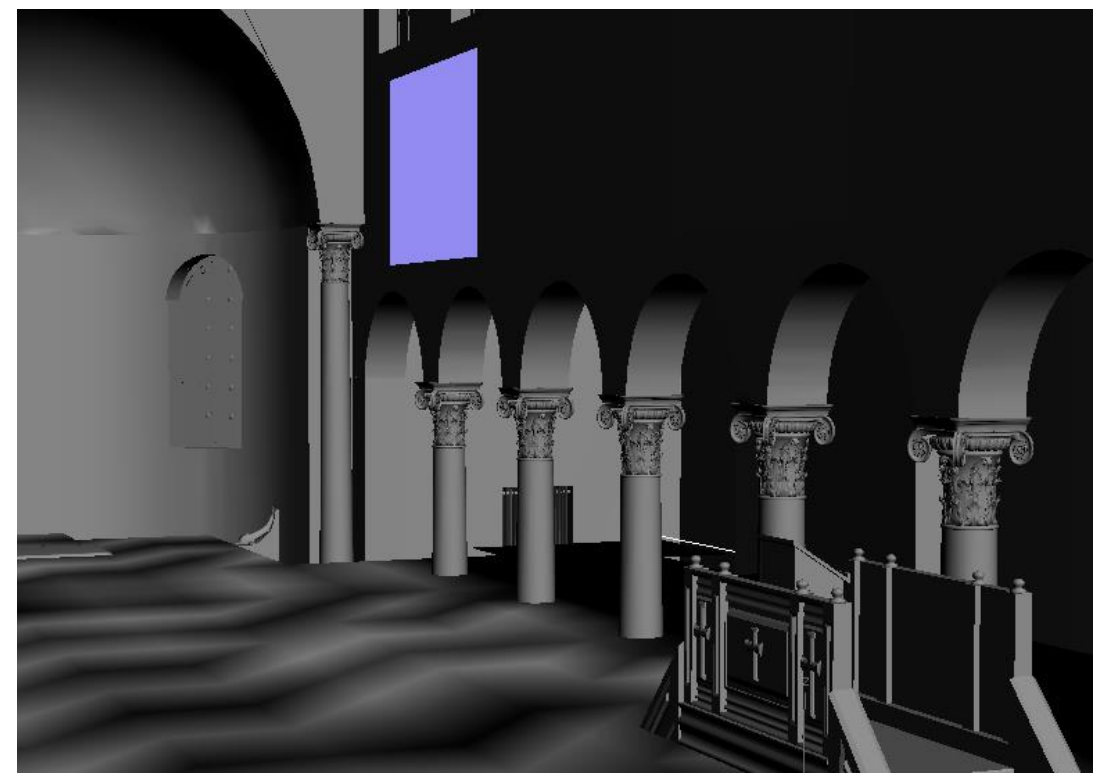

Figure 22. Visibility of hypothesised painting, with $2 \mathrm{~m}$ voxel layer reclassified according to angular prominence of the painting 


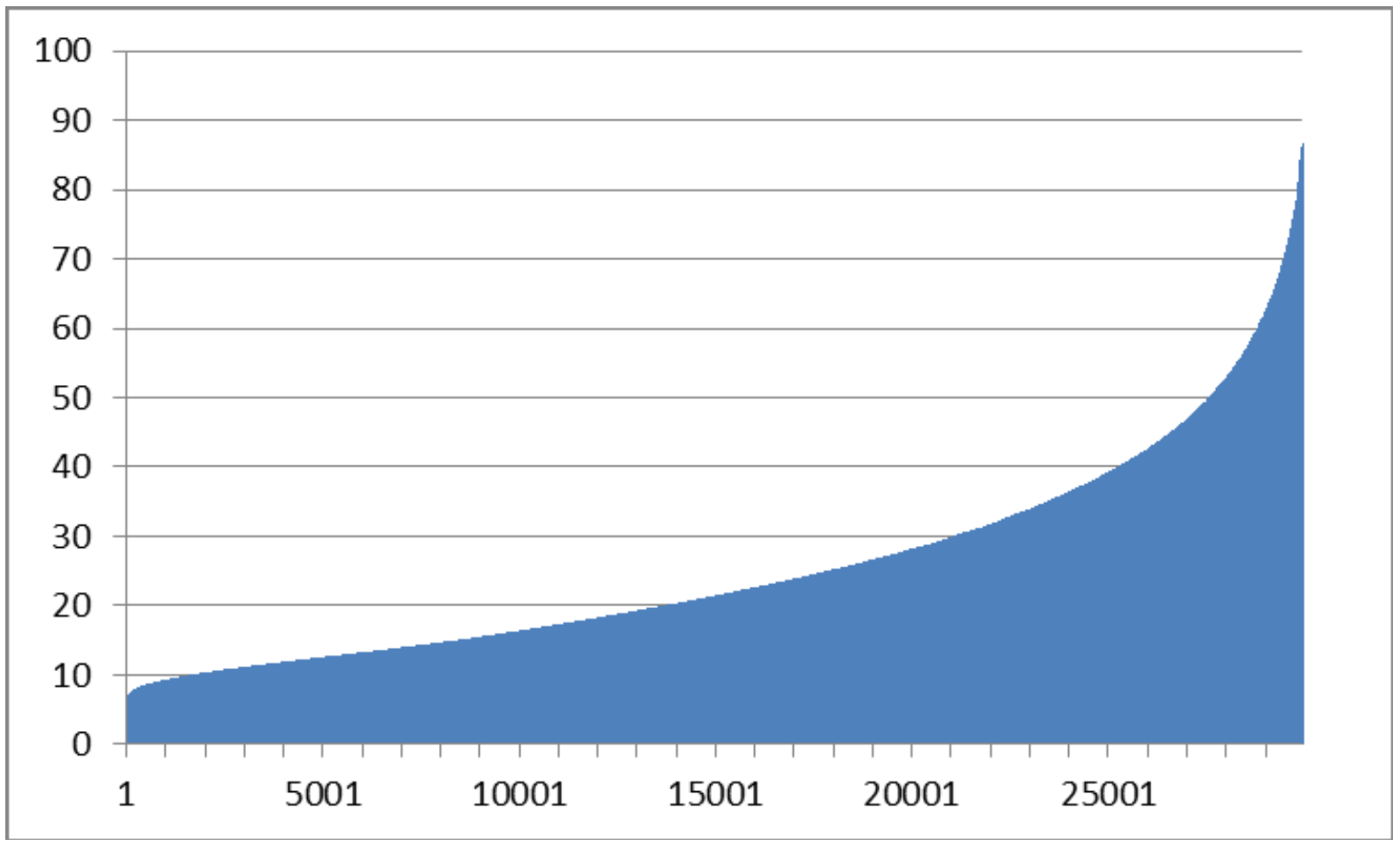

Figure 23. Graph showing angular visibility of one of the hypothesised clerestorey paintings ( $Y$ axis shows observer angle of view; $\mathrm{X}$ axis observer)

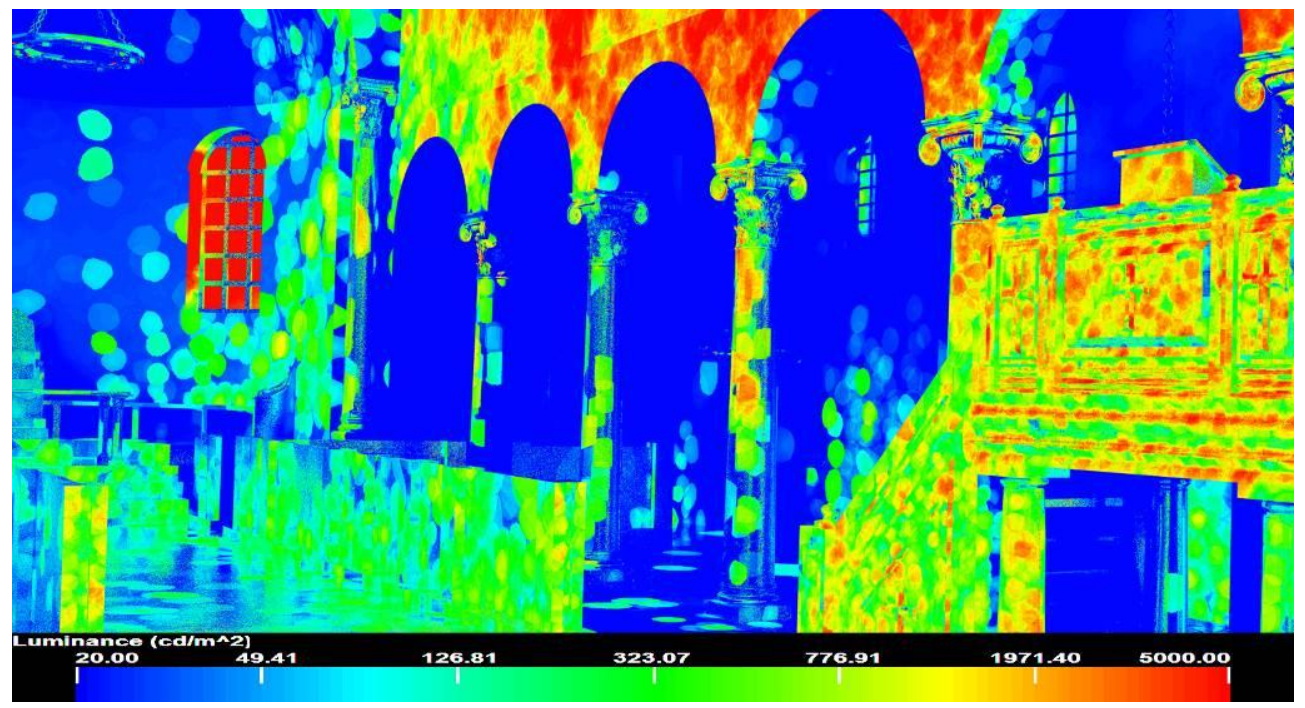

Figure 24. Pseudo-colour exposure of an alternative structural model with windows at the east aisle. 


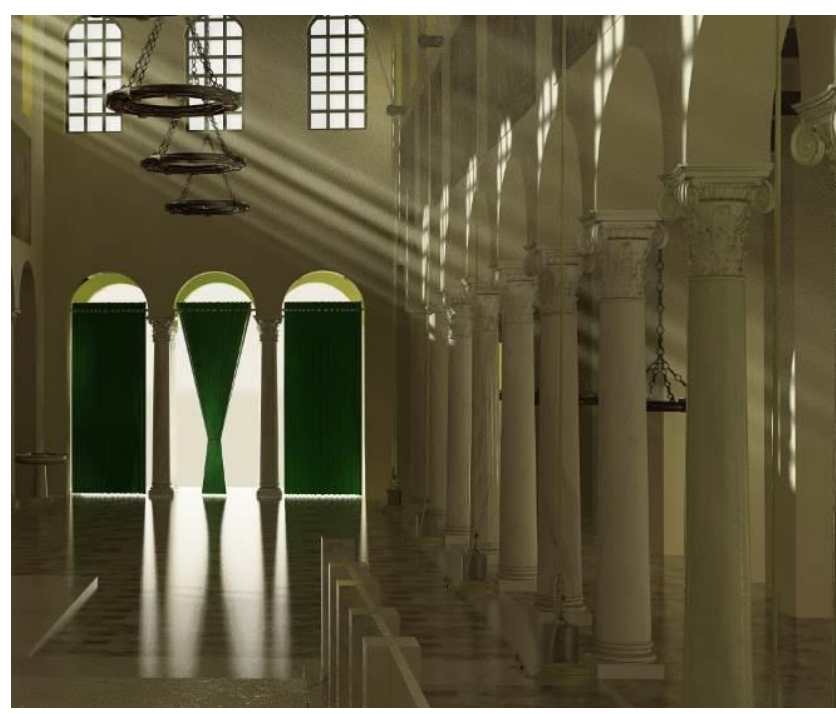

Figure 25. Render showing atmospheric effects

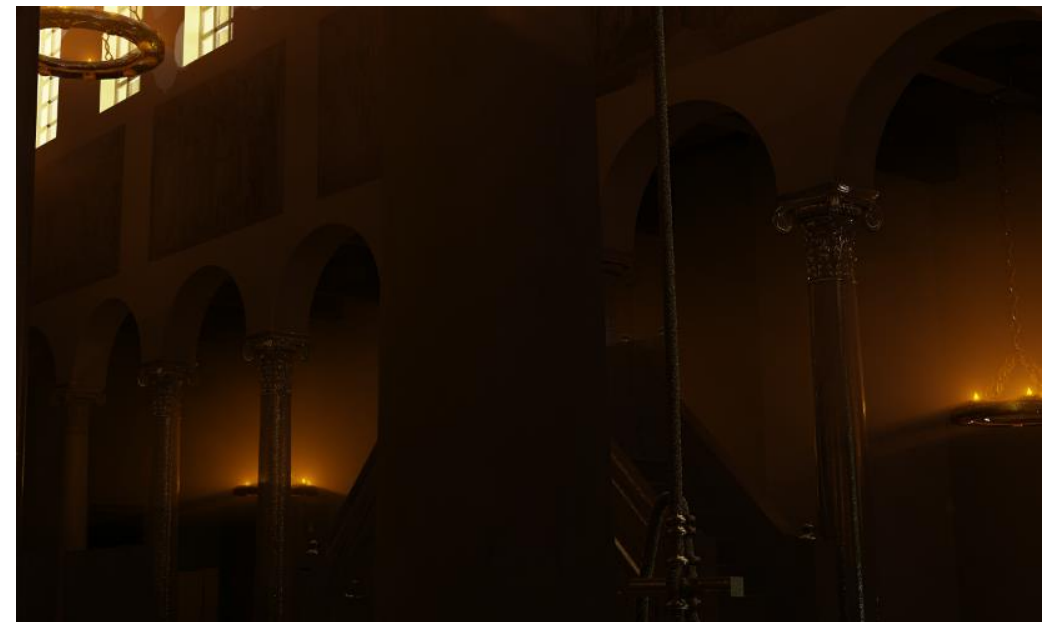

Figure 26. Illustrative render showing Basilica Portuense under artificial illumination (Note: we do not currently have sufficient data to render physically accurate simulations of artificial illumination in this model). 